\title{
University
}

Lopez-Gimenez, J., Alvarez-Curto, E., and Milligan, G. (2017) M3 muscarinic acetylcholine receptor facilitates the endocytosis of mu opioid receptor mediated by morphine independently of the formation of heteromeric complexes. Cellular Signalling, 35 , pp. 208-222.

There may be differences between this version and the published version. You are advised to consult the publisher's version if you wish to cite from it.

http://eprints.gla.ac.uk/140300/

Deposited on: 8 May 2017

Enlighten - Research publications by members of the University of Glasgow http://eprints.gla.ac.uk 


\section{M3 muscarinic acetylcholine receptor facilitates the endocytosis of mu opioid receptor mediated by morphine independently of the formation of heteromeric complexes.}

Juan F. Lopez-Gimenez ${ }^{1 \text { }^{*}}$, Elisa Alvarez-Curto² and Graeme Milligan ${ }^{2}$

${ }^{1}$ Institute of Biomedicine and Biotechnology of Cantabria, (IBBTEC), CSIC, Santander, Spain.

${ }^{2}$ Molecular Pharmacology Group, Institute of Molecular, Cell, and Systems Biology, College of Medical, Veterinary and Life Sciences, University of Glasgow, Glasgow, Scotland, United Kingdom.

- Present address: Center for Research in Molecular Medicine and Chronic Diseases (CIMUS), University of Santiago de Compostela (USC), Santiago de Compostela, Spain.

"corresponding author: Juan F. Lopez-Gimenez

CIMUS-USC. Av. Barcelona s/n. 15782 Santiago de Compostela.

Spain.

tel.: +34654356248

email: jf.lopez.gimenez@csic.es 


\section{Abstract}

Morphine inefficiency to induce the internalization of mu opioid (MOP) receptors observed in numerous experimental models constitutes a paradigm of G-protein coupled receptor (GPCR) functional selectivity. We recently described that activation of $\mathrm{G}_{\alpha \mathrm{q} / 11}$ proteins through 5-HT $2 \mathrm{~A}$ serotonin receptors co-expressed in the same cells facilitates MOP receptor endocytosis promoted by morphine. In order to explore whether a different $G_{\alpha q / 11}$ coupled GPCR would emulate this effect, a double stable Flp-In T-REx HEK293 cell line permanently expressing MOP-YFP receptors along with FLAG-M3-Cerulean receptors expressed in an inducible manner was generated. Fluorescence microscopy examination of these cells revealed a co-distribution of both receptors mainly compartmentalized in plasma membrane. Concurrent stimulation with carbachol and morphine promoted MOP receptor internalization, desensitization and down-regulation by morphine and this facilitation was not dependent on PKC activation. Co-immunoprecipitation experiments demonstrated that FLAG-M3-Cerulean/MOP-YFP receptors interact in heteromeric complexes in a time depending manner, i.e. the strongest interaction was detected after 96 hours of FLAG-M3Cerulean induced expression. Under these experimental conditions, treatment of cells with carbachol plus morphine resulted in the internalization of both receptors within separated endocytic vesicles as visualized by confocal microscopy. This trafficking segregation observed for FLAG-M3-Cerulean and MOP-YFP receptors upon agonist stimulation suggests that this protein-protein interaction presents temporal and dynamic properties. Moreover, MOP-YFP receptor internalization facilitated by FLAG-M3-Cerulean receptors is independent of the constitution of heteromeric complexes.

Keywords: MOP receptor, M3 receptor, GPCR, morphine, Heteromerization, Endocytosis 


\section{Introduction}

The molecular pharmacology study of G-protein coupled receptors (GPCRs) during the last two decades has been principally focused on two aspects, namely receptor oligomerization and functional selectivity or biased agonism. The idea that family A receptors might constitute quaternary structures in form of dimer or higher order oligomers is widely accepted at the moment [1], although both the structural basis of the formation of such multiprotein arrangements and the functional consequences of these protein-protein interactions still constitute a topic of scientific investigation and debate [2]. This complexity in the receptor oligomeric organization escalates when considering the possibility of the formation of multimeric complexes constituted by different monomeric entities. In this sense and in general, homodimers seem to be the prevailing arrangement with the potential to form higher order oligomers, especially tetramers. However, in the case of heteromers, it is still obscure if such heterocomplexes are preferentially heterodimers or if they are mainly constituted by heteromers of homodimers [1]. On the other hand, the notion of functional selectivity refers to the property of some ligands to induce unique, ligand-specific receptor conformations that commonly can result in different activation of signal transduction pathways associated with that particular receptor. This differential activation might be expressed in differences in intrinsic activity and/or potency at one signalling pathway in relation to another that are not due to differences in affinity at the mediating receptor [3]. In fact, receptor oligomerization and functional selectivity are intimately related since the participation of monomeric units in heterocomplexes may confer novel properties to the agonist-directed trafficking of the signalling response mediated by those receptors. In relation to mu opioid (MOP) receptors, functional selectivity has been extensively described at different levels of their activity such as G-protein coupling, phosphorylation of intracellular domains, interactions with $\beta$-arrestins, receptor desensitisation and internalisation [4]. Particularly in the case of MOP receptors, 
there is a marked functional selectivity with regards the ability exhibited by some ligands to promote receptor internalization. In this sense, morphine constitutes one of the most paradigmatic models since it has been observed inefficacy to facilitate MOP receptor endocytosis in numerous cell systems when in fact it resulted competent in other biological responses mediated by the receptor activation and subsequent coupling to G-proteins in those same cells (for a review on this topic see [5]). Moreover, Whistler and collaborators propose a hypothesis asserting that the incapacity of morphine to endocytose MOP receptor after its activation constitutes the molecular basis of the development of tolerance to this opiate when used in prolonged treatments [6]. These authors went further on demonstrating that using morphine in combination with other opioids in such a way that the internalization of MOP receptors were promoted or by exchanging the C-terminus portion of MOP receptors by the equivalent domain from DOP receptors obtaining a chimeric receptor capable to endocytose with morphine, in both cases the validation of these results to physiological in vivo models resulted in a significant reduction of the development of tolerance to morphine in animals submitted to chronic treatments in nociception experiments [7-9]. Nevertheless, it is well accepted at the moment that tolerance is rather a multifaceted process involving multiple regulatory elements occurring both at the level of individual opioid-responsive cells and at the most complex level of neural circuits [10]. At the cellular level, and more particularly in heterologous expression models, there is evidence describing the overexpression of accessory proteins involved in the internalization/desensitization of receptors such as GRKs and ßarrestins as facilitators of MOP receptor endocytosis by morphine [11,12]. In a similar way and more recently, we described that the co-activation of serotonin $5-\mathrm{HT}_{2} \mathrm{~A}$ receptors facilitated the desensitization, down-regulation and internalization of MOP receptors promoted by morphine when both receptors are co-expressed in Flp-In T-Rex 293 cells [13]. In relation to the facilitation of the endocytosis, that result was equivalently obtained with the 
high homologous 5- $\mathrm{HT}_{2 \mathrm{C}}$ receptor [14]. During the course of our studies with 5- $\mathrm{HT}_{2 \mathrm{~A}}$ receptors, we demonstrated that the inhibition of its coupling to $G \alpha_{\mathrm{q} / 11}$ proteins by using the YM254890 compound aborted the facilitation of MOP receptor endocytosis by morphine [13]. In the present study we aimed to assess whether a different receptor coupled preferentially to $\mathrm{G} \alpha_{\mathrm{q} / 11}$ proteins would emulate the effect of the concomitant activation of 5$\mathrm{HT}_{2 \mathrm{~A}}$ receptor on desensitization, internalization and down-regulation of MOP receptors mediated by morphine. The receptor of choice for this purpose was the M3 muscarinic acethylcholine receptor, essentially because M3 is a family A GPCR that couples preferentially to $G \alpha_{\mathrm{q} / 11}$ proteins and there are preliminary results supporting its co-expression with MOP receptors in neural tissue, particularly in the locus coeruleus [15-17]. In addition, a pharmacological interaction between both M3 and MOP receptors has been already described in that particular brain area in relation to the desensitization of MOP receptors mediated by M3 receptor activation $[18,19]$. Our results herein indicate that M3 receptors when coactivated might facilitate the internalization, desensitization and down-regulation of MOP receptors mediated by morphine in a manner that is independent of PKC activation. Furthermore, M3 and MOP receptors might interact to each other to form heterocomplexes that are not necessary for the pharmacological interaction between both receptors.

\section{Materials and Methods}

\subsection{Materials}

All reagents for cell culture and Flp-In ${ }^{\mathrm{TM}} \mathrm{T}-\mathrm{REx}^{\mathrm{TM}} 293$ cells were from Invitrogen (Paisley, UK). $\left[{ }^{3} \mathrm{H}\right]$ diprenorphine and $\left[{ }^{3} \mathrm{H}\right] \mathrm{QNB}$ were from PerkinElmer Life and Analytical Sciences (Boston, MA). Doxycycline, carbachol, atropine, morphine, naloxone, DAMGO, Ro31-8220 and chelerythrine were from SIGMA-Aldrich. 


\subsection{Receptor Fusions with Fluorescent proteins}

Generation and subcloning of the human version of M3 muscarinic acetylcholine receptor construct was basically as described previously [20]. Briefly, the FLAG epitope tag was added at the amino terminus of the receptor by means PCR techniques using a forward primer containing the sequence of FLAG epitope (amino acid sequence DYKDDDDK). Afterwards, FLAG-M3 receptor was tagged at the carboxyl terminus with Cerulean fluorescent protein by amplifying the sequence corresponding to the receptor and removing the stop codon by PCR. The final product of this construction corresponds to a single open reading frame encoding for the receptor-fluorescent protein fusion. FLAG-M3-Cerulean was subcloned into the vector pcDNA5/FRT/TO (Invitrogen) for the subsequent generation of Flp-In T-REx HEK293 inducible cell lines. MOP-YFP receptor [13] was obtained after amplification of human MOP receptor using PCR primers containing a SacI endonuclease site at the 5'end and an ApaI endonuclease site at the 3 'end and removing in the process the stop codon. This PCR product was subsequently subcloned into peYFP-N1 vector resulting in a single open reading frame consisting of the MOP receptor with eYFP fused to the carboxyl terminus. All these constructs were verified by DNA sequencing.

\subsection{Generation of Stable Flp-In T-REx HEK293 Cell Lines}

In order to generate Flp-In T-REx HEK293 cell lines able to express FLAG-M3-Cerulean receptors in an inducible manner we followed the detailed protocol described elsewhere [21]. Briefly, cells were transfected with a mixture containing the FLAG-M3-Cerulean receptor cDNA into pcDNA5/FRT/TO vector and pOG44 vector in a ratio 1:9 using Effectene transfection reagent (QIAGEN, Hilden, Germany) according to the manufacturer's instructions. When cotransfected with pcDNA5/FRT plasmid into the Flp-In mammalian host cell line, the Flp recombinase expressed from pOG44 mediates integration of the 
pcDNA5/FRT vector containing the gene of interest into the genome via Flp recombination target (FRT) sites. Cell maintenance and selection were as described previously [22]. Clones resistant to blasticidin were screened for FLAG-M3-Cerulean espression by both fluorescence presence and Western blotting. Cells were treated with varying concentrations of doxycycline for different periods in order to induce expression of FLAG-M3-Cerulean receptors. The optimal expression was achieved after 24 hours of treatment with $0.01 \mu \mathrm{g}$ of doxycycline $/ \mathrm{ml}$ growth medium (see Results). A double stable cell line expressing MOP-eYFP constitutively and FLAG-M3-Cerulean in an inducible manner was generated from the Flp-In T-REx HEK293 cells described above. Cells were transfected using Effectene (QIAGEN) with the vector containing MOP-YFP. After transfection, cells were selected for resistance to Geneticin (G418; 1mg/ml), and the resistant clones were screened for receptor expression by fluorescence microscopy.

\subsection{Living Cell Epifluorescence Microscopy}

Cells expressing receptors tagged with Cerulean or eYFP were grown onto poly-lysine-treated coverslips. These coverslips were placed into a microscope chamber containing physiological saline solution (130 mM NaCl, $5 \mathrm{mM} \mathrm{KCl}, 1 \mathrm{mM} \mathrm{CaCl} 2,1 \mathrm{mM} \mathrm{MgCl}_{2}, 20 \mathrm{mM}$ HEPES, and 10 mM D-glucose, pH 7.4). Cell fluorescent images were acquired using a TE2000-E inverted microscope (Nikon, Melville, NY) equipped with a 40X (numerical aperture, 1.3) oil immersion Plan Fluor lens and a cooled digital CoolSNAP ${ }_{H Q}$ charge-coupled device camera (Photometrics, Tucson, AZ). For internalisation experiments in real time, drugs diluted in physiological saline solution were perfused into the microscope chamber and pictures were taken every 3 minutes during a period of 30 to 35 minutes. 


\subsection{Cell Membrane Preparation}

Harvested pellets from Flp-In T-REx HEK293 cells kept at $-80^{\circ} \mathrm{C}$ were thawed and resuspended in $10 \mathrm{mM}$ Tris and $0.1 \mathrm{mM}$ EDTA, $\mathrm{pH} 7.4$ (Tris/EDTA buffer). Cells were homogenised by 25 passes of a glass-on-Teflon homogeniser. The resulting suspension was centrifuged at $1200 \mathrm{~g}$ for $10 \mathrm{~min}$ to remove cellular debris and nuclei. The supernantant was subsequently centrifuged at 218,000g for $30 \mathrm{~min}$ in an Optima TLX ultracentrifuge (Beckman Coulter, Fullerton, CA). Resulting pellets were resuspended in Tris/EDTA buffer and passed through a 25-gauge needle. Protein concentration was determined and the membranes were stored at $-80^{\circ} \mathrm{C}$ until use.

\subsection{Radioligand Binding Assays}

$\left[{ }^{3} \mathbf{H}\right]$ QNB Binding. Saturation binding curves were initiated by the addition of $1 \mu \mathrm{g}$ of membrane protein to assay buffer (20 mm HEPES, $100 \mathrm{~mm} \mathrm{NaCl}$, and $10 \mathrm{~mm} \mathrm{MgCl}$, $\mathrm{pH} 7.4$ ) containing varying concentrations of $\left[{ }^{3} \mathrm{H}\right] \mathrm{QNB}(50.5 \mathrm{Ci} / \mathrm{mmol})$, i.e. nine points ranged from $0.01 \mathrm{nM}$ to $0.45 \mathrm{nM}$. Nonspecific binding was determined in the presence of $10 \mu \mathrm{m}$ atropine. Every point was performed in triplicate. Reactions were incubated for 90 min at $25{ }^{\circ} \mathrm{C}$, and bound ligand was separated from free by vacuum filtration through GF/C filters (Brandel Inc., Gaithersburg, MD). The filters were washed twice with assay buffer, and bound ligand was estimated by liquid scintillation spectrometry.

2.7. $\left[{ }^{3} \mathbf{H}\right]$ Diprenorphine Binding. Cell membranes (15-20 $\mu \mathrm{g}$ of protein) were incubated with $\left[{ }^{3} \mathrm{H}\right]$ diprenorphine (0.02-2 $\mathrm{nM}$ in saturation assays; $1-2 \mathrm{nM}$ in single point assays) in a total volume of $1 \mathrm{ml}$ of buffer (50 mM Tris- $\mathrm{HCl}, 1 \mathrm{mM}$ EDTA, and $10 \mathrm{mM} \mathrm{MgCl}, \mathrm{pH} 7.4$ ). Nonspecific binding was determined by the inclusion of $100 \mu \mathrm{M}$ naloxone. Every point was performed in triplicate. Binding was initiated by the addition of membranes, and the tubes 
were incubated at $25^{\circ} \mathrm{C}$ for $60 \mathrm{~min}$. The assay was terminated by rapid filtration using a cell harvester (Brandel Inc.) with three 5-ml washes of ice-cold phosphate-buffered saline. The filters were soaked in $3 \mathrm{ml}$ of scintillation fluid, and radioactivity was determined by liquid scintillation spectrometry.

\section{8. $\left[\mathrm{Ca}^{2+}\right]_{i}$ Measurements}

Cells were seeded into 96-well plates, loaded with the $\mathrm{Ca}^{2+}$-sensitive dye FURA-2 acetoxymethyl ester $(1.5 \mu \mathrm{M})$ by incubation $\left(30 \mathrm{~min} ; 37^{\circ} \mathrm{C}\right)$ under reduced light in DMEM medium. Calcium imaging and analysis were then performed using a FLEXstation (Molecular Devices, Sunnyvale, CA).

\subsection{IP-1 Accumulation Measurements}

Cells expressing receptors tagged with Cerulean and eYFP were either induced for 24 hours with 10 ng. $\mathrm{mL}^{-1}$ of doxycycline or left untreated. Cells were harvested using Versene dissociation reagent, washed, resuspended in Hank's Buffered Salt Solution (HBSS) and subsequently added to 384-well low volume Optiplates to a final cell density of 9800 cells/well. Cells were stimulated with variable concentrations of carbachol for 30 min at $37^{\circ} \mathrm{C}$.

Detection of IP-1 accumulation was carried out for 1 hour at room temperature and protected form the light, using the IP-One Tb kit (Cisbio Bioassays, Bagnols-sur-Cèze, France) according to the manufacture's instructions. Plates were read using a PheraStar FS (BMG Labtechnologies, Offenburg, Germany).

\subsection{Western Blotting}

Samples were heated at $65^{\circ} \mathrm{C}$ for $14 \mathrm{~min}$ and subjected to SDS-polyacrylamide gel electrophoresis analysis using 4 to $12 \%$ bis-Tris gels (NuPAGE, Invitrogen) and MOPS 
buffer. After electrophoresis, proteins were transferred onto nitrocellulose membranes that were incubated in a solution of 5\% non-fat milk and $0.1 \%$ Tween-20 in Tris-buffered saline at room temperature on a rotating shaker for 2 hours to block nonspecific binding sites. Afterwards, membranes were incubated overnight with a rabbit anti-FLAG polyclonal antibody (SIGMA-Aldrich) or a sheep anti-MOP antiserum generated in house [22]. Protein antibody interactions were detected using horseradish peroxidise-linked anti-rabbit IgG or anti-goat IgG secondary antisera (GE Healthcare, Chaltfont St. Giles, Buckinghamshire, UK). Immunoblots were developed by application of enhanced chemiluminescence solution (ECL, Pierce Chemical Rockford, IL).

\subsection{Biotinylation Protection Assay}

Cells growing on culture dishes were treated with $0.3 \mathrm{mg} / \mathrm{ml}$ disulfide-cleavable biotin (Pierce Chemical Rockford, IL) in phosphate buffered saline (PBS) at $4^{\circ} \mathrm{C}$ for $30 \mathrm{~min}$. After washing with fresh PBS, cells were pre-treated with warmed growth medium $\left(37^{\circ} \mathrm{C}\right)$ for $15 \mathrm{~min}$. Afterwards, cells were treated with drugs during at least $30 \mathrm{~min}$ to promote receptor endocytosis and meanwhile the cells corresponding to either $100 \%$ of biotinylation as stripping control were kept at $4^{\circ} \mathrm{C}$ in PBS. After agonist treatment, cells were washed with PBS at $4^{\circ} \mathrm{C}$ and the biotinylated receptors were stripped with a buffer containing $50 \mathrm{mM}$ glutathione, $0.3 \mathrm{M} \mathrm{NaCl}, 75 \mathrm{mM} \mathrm{NaOH}$ and $1 \%$ FBS. Samples were then washed with PBS at $4^{\circ} \mathrm{C}$ and cell extracts were made in $0.1 \%$ Triton $\mathrm{X}-100,150 \mathrm{mM} \mathrm{NaCl}, 25 \mathrm{mM} \mathrm{KCl}$ and 10 $\mathrm{mM}$ Tris- $\mathrm{HCl}(\mathrm{pH}$ 7.4). Cellular debris was removed by centrifugation at $10,000 \mathrm{~g} \times 10 \mathrm{~min}$ at $4^{\circ} \mathrm{C}$ and cell lysates were immunoprecipitated with immobilised Neutravidin protein (Pierce Chemical Rockford, IL) for at least 1 hour at $4^{\circ} \mathrm{C}$. After washing with fresh lysis buffer, samples were processed for Western Blotting. 


\subsection{Co-Immunoprecipitation Assay}

Harvested cells were resuspended in RIPA buffer (50 mM HEPES, $150 \mathrm{mM} \mathrm{NaCl}, 0.5 \%$ sodium deoxycholate, $0.1 \%$ SDS, $1 \%$ Triton X-100, $10 \mathrm{mM} \mathrm{NaF,} 5 \mathrm{mM}$ EDTA, $0.1 \mathrm{mM}$ $\mathrm{NaPO}_{4}, 5 \%$ ethylene glycol) containing Complete protease inhibitors mixture (Roche Diagnostics). Cells were placed on a rotating wheel for $1 \mathrm{~h}$ at $4{ }^{\circ} \mathrm{C}$. Samples were then centrifuged for $1 \mathrm{~h}$ at $100,000 \times \mathrm{g}$ at $4{ }^{\circ} \mathrm{C}$, and the supernatant was transferred to a fresh tube containing $50 \mu \mathrm{l}$ of protein $\mathrm{G}$ beads (Sigma) to pre-clear the samples. Following incubation on a rotating wheel for $1 \mathrm{~h}$ at $4{ }^{\circ} \mathrm{C}$, the samples were re-centrifuged at $20,800 \times g$ at $4{ }^{\circ} \mathrm{C}$ for 1 min, and the protein concentration of the supernatant was determined. Samples containing equal protein amounts were incubated overnight with $40 \mu \mathrm{l}$ of protein $\mathrm{G}$ beads and the immunoprecipitating antibody $\left(2 \mu \mathrm{l}\right.$ of sheep anti-MOP) at $4{ }^{\circ} \mathrm{C}$ on a rotating wheel, and fractions were reserved to monitor protein expression in the cell lysates. Samples were centrifuged at 20,800 $\mathrm{xg}$ for $1 \mathrm{~min}$ at $4{ }^{\circ} \mathrm{C}$, and the protein $\mathrm{G}$ beads were washed three times with RIPA buffer. Afterwards samples were processed for Western Blotting.

\subsection{Co-localization Studies by Confocal Microscopy}

Flp-In T-REx HEK293 cells expressing both FLAG-M3-Cerulean and MOP-eYFP receptors were submitted to the different agonist treatments during $30 \mathrm{~min}$ at $37{ }^{\circ} \mathrm{C}$ and subsequently they were fixed with 4\% paraformaldehyde solution in PBS for 10 minutes at room temperature. After fixation, cells were rinsed with PBS at room temperature, mounted onto slides and kept until confocal microscopy examination. Confocal images, (512x512 pixels; $0.07 \mathrm{~mm}$ pixel size) were acquired sequentially on a SP5 laser-scan microscope (Leica) with a 63x 1.4 NA objective, a 2 Airy Units pinhole, x7 electronic zoom and 400Hz speed using LAS AF acquisition software. Cells were excited sequentially with $458 \mathrm{~nm}$ and $514 \mathrm{~nm}$ laser lines and emission captured between 465-500nm (CFP) and 525-575nm (YFP). Images are 
presented after digital adjustment of contrast to maximize signal with ImageJ software. In all cases, exposure time, sensor gain, and digital manipulation were the same for control and experimental samples. Co-localization analysis was carried out with ImageJ software by using the JACoP plugging described elsewhere [23]. Particularly, Pearson's correlation coefficient was used to compare the overlapping degree between images obtained with the different fluorophore light settings.

\subsection{Quantitative Analysis of Endocytosis by Epifluorescence Microscopy}

Flp-In T-REx HEK293 cells permanently expressing MOP-YFP receptors and treated at different time points from 24 hours to 120 hours with doxycycline $\left(10 \mathrm{ng} . \mathrm{mL}^{-1}\right)$ to induce the expression of FLAG-M3-Cerulean receptors were grown on poly-d-lysine-treated coverslips. Coverslips were placed into a microscope chamber containing physiological saline solution (130 mM NaCl, $5 \mathrm{mM} \mathrm{KCl}, 1 \mathrm{mM} \mathrm{CaCl}_{2}, 1 \mathrm{mM} \mathrm{MgCl} 2,20 \mathrm{mM}$ HEPES, and $10 \mathrm{mM}$ Dglucose, $\mathrm{pH}$ 7.4). To conduct internalisation experiments in real time, drugs were diluted in physiological saline solution and perfused into the microscope chamber and 15 planes of 0.49 $\mu \mathrm{m}$ Z-step size were acquired for 15 minutes at a rate of 1 frame per minute in an inverted epifluorescence microscope (AF6500; Leica Microsystems) equipped with temperature control $(\mathrm{PeCon} \mathrm{GmbH})$ at $37{ }^{\circ} \mathrm{C}$. Cell fluorescence was visualized with a $63 \times 1.3$ NA oil objective, 470/40 excitation and 515LP emission filters, and images (1004x1002 pixels; 0.13 $\mu \mathrm{m}$ pixel size) were acquired with a DU8285_VP (Andor Technology) camera using exposures of $200 \mathrm{~ms}$ or less and an EM Gain of 20. Images were subsequently analysed with the Q_Endosomes algorithm previously described [14] by using ImageJ and Matlab software. 


\subsection{Data Analysis}

Data were analyzed using Prism (GraphPad Software Inc., San Diego, CA), and statistical significance was determined using either Student's $t$ test or one-way/two-way ANOVA followed by the post hoc analysis as appropriate. $P<0.05$ determined statistical significance. This study is essentially exploratory, therefore statistics analysis is descriptive only. When not indicated, error bars correspond to standard deviation (SD).

\section{Results}

\subsection{Generation and characterization of a Flp-In T-Rex 293 cell line harbouring the $M_{3}$} receptor at the inducible locus and constitutively expressing the MOP receptor

An example of a clone from the cell line generated as described in Methods section is shown in Figure 1A. Both in the absence and presence of doxycycline YFP fluorescence corresponding to MOP-YFP was present and largely at the surface of cells, whilst CFP fluorescence corresponding to FLAG-M3-Cerulean was observed only following treatment with doxycycline (Figure 1A). Addition of varying concentrations of doxycycline to these cells followed by immunoblotting of SDS-PAGE resolved membranes revealed concentration-dependent expression of FLAG-M ${ }_{3}$-Cerulean (Figure 1B), with maximal expression produced by some 10 ng. $\mathrm{mL}^{-1}$ doxycycline. Equivalent immunoblots with an antiMOP receptor antibody confirmed constitutive expression of MOP-YFP and that this was apparently unaltered by the induced expression of $\mathrm{FLAG}_{3}-\mathrm{M}_{3}-$ Cerulean (Figure 1B). Following addition of doxycycline expression of FLAG-M 3 -Cerulean could be detected within 24 hours and over longer time periods expression levels continued to increase gradually (Figure 2). Details of the expression levels of the two receptors were obtained via $\left[{ }^{3} \mathrm{H}\right]$ ligand binding studies. Saturation binding studies performed with the muscarinic 
antagonist $\left[{ }^{3} \mathrm{H}\right] \mathrm{QNB}$ on membranes from cells induced with $10 \mathrm{ng} \cdot \mathrm{mL}^{-1}$ doxycycline for $24 \mathrm{~h}$ identified a single saturable binding site of $4125+/-591 \mathrm{fmol} / \mathrm{mg}$ protein and an affinity constant $\left(\mathrm{K}_{\mathrm{d}}\right)$ of $0.087 \pm 0.01 \mathrm{nM}$ (means $+/-$ SEMs, $\mathrm{n}=5$ ) (Figure 3A). Equivalent experiments performed with samples from uninduced cells generated a $B_{\max }$ of $430 \mathrm{fmol} / \mathrm{mg}$ protein. These sites are likely to represent endogenously expressed muscarinic receptors [24] as neither imaging for CFP nor anti-FLAG immunoblots suggested leak of expression of FLAG-M3-Cerulean in the absence of doxycycline (Figure 1). Levels of MOP-YFP were assessed via saturation $\left[{ }^{3} \mathrm{H}\right]$ diprenorphine binding assays. In the absence of doxycycline treatment a single saturable specific binding site corresponding to $1374 \pm 215 \mathrm{fmol} / \mathrm{mg}$ protein with $\mathrm{K}_{\mathrm{d}}=0.24 \pm 0.02 \mathrm{nM}(\mathrm{n}=5)$ was observed. Following doxycycline treatment the level of MOP-eYFP increased ( $\mathrm{t}$-test $\mathrm{P}=0.0321)$ to $2345 \pm 307 \mathrm{fmol} / \mathrm{mg}$ membrane protein (n =5) with a modest decrease (t-test $P=0.1962), K_{d}=0.37 \pm 0.09 n M$, in affinity for this ligand (Figure 3B).

The muscarinic $M_{3}$ receptor couples preferentially to heterotrimeric $G \alpha_{q} / 11$ proteins and this results in mobilization of intracellular calcium. Initial downstream signalling from the activation of $\mathrm{G} \alpha_{\mathrm{q} / 11}$ proteins leads to phospholipase $\mathrm{C}$ activation and the production of inositol 1, 4, 5-tri-phosphate (IP3) and diacylglicerol. We measured this pathway in cells coexpressing FLAG-M 3 -Cerulean and MOP-YFP initially by recording the accumulation of myo-inositol 1-phosphate, a product of IP3 degradation, after agonist treatment. In doxycycline-induced cells the muscarinic agonist carbachol elicits a substantial response $\left(\mathrm{pEC}_{50}=5.80 \pm 0.24\right.$, mean $\left.+/-\mathrm{SEM}, \mathrm{n}=3\right)$ (Figure 3C), that is greatly reduced in the uninduced cells $\left(\mathrm{pEC}_{50}=3.64 \pm 0.07\right.$, mean $+/-\mathrm{SEM}, \mathrm{n}=3$ ) (Figure 3C). Measurement of further downstream signalling by means of monitoring intracellular calcium $\left(\left[\mathrm{Ca}^{2+}\right]_{\mathrm{i}}\right)$ release shows that carbachol potently elevates $\left[\mathrm{Ca}^{2+}\right]_{\mathrm{i}}$ in doxycycline-induced cells $\left(\mathrm{pEC} \mathrm{C}_{50}=7.95 \pm\right.$ 0.05 , mean $+/-$ SEM, $\mathrm{n}=3$ ). However, consistent with the endogenous expression of a 
muscarinic receptor population, carbachol also elevated $\left[\mathrm{Ca}^{2+}\right]_{\mathrm{i}}$ in uninduced cells but with substantially lower potency $\left(\mathrm{pEC}_{50}=5.69 \pm 0.08, \mathrm{n}=3\right)($ Figure 3D).

\subsection{Desensitization and internalization studies on MOP-YFP receptors}

Cells induced to express FLAG-M ${ }_{3}$-Cerulean were treated at varying times with either morphine $(1 \mu \mathrm{M})$, carbachol $(1 \mathrm{mM})$ or concurrently with a combination of morphine and carbachol. Following removal of the ligands, membranes prepared from these cells were employed in $\left[{ }^{35} \mathrm{~S}\right] \mathrm{GTP} \gamma \mathrm{S}$ binding assays to assess activation of $\mathrm{G}_{\mathrm{i}}$-family G-protein in response to varying concentrations of morphine. Pre-treatment with morphine for up to 4 hours did not alter the apparent efficacy or potency of morphine (Figure 4A, Table 1). This was also the case after pre-treatment with carbachol (Figure 4B, Table 1). In contrast, concurrent treatment with morphine plus carbachol caused a marked reduction in the potency of morphine (Figure 4C, Table 1) that was maximal within 30 minutes and maintained at longer times of pre-treatment. This effect was also observed in relation to the efficacy of morphine, particularly within the first 60 min of pre-treatment (Figure 4C, Table 1). In many circumstances sustained treatment with morphine fails to cause down-regulation of the MOP receptor. Indeed, in cells induced to co-express FLAG-M 3 -Cerulean and MOP-eYFP, treatment with morphine for up to 4 hours did not result in a downregulation of MOP-YFP levels (Figure 4D). By contrast treatment with the combination of morphine and carbachol did cause loss of some $30 \%$ of the $\left[{ }^{3} \mathrm{H}\right]$ diprenorphine binding sites and this reached maximal levels within a 2 hour treatment period (Figure 4D).

Morphine also failed to produce internalization of MOP-YFP from the surface of cells, whether MOP-YFP was expressed in the absence (data not shown) or the presence (Figure 5) of FLAG-M 3 -Cerulean. By contrast, and as noted previously in such transfected Flp-In TRex 293 cells [13], DAMGO produced extensive internalization of MOP-YFP in both 
situations (Figure 5) but did not cause detectable internalization of FLAG-M3-Cerulean when the two receptors were co-expressed. Carbachol was also unable to cause internalization of MOP-YFP when cells were induced to co-express the two receptors and, indeed had little capacity to cause internalization of FLAG-M3-Cerulean in these studies (Figure 5). However, as anticipated from the down-regulation studies, co-addition of carbachol and morphine resulted in internalization of MOP-YFP in cells induced to co-express the two receptors (Figure 5), although this still did not result in substantial internalization of FLAG-M 3 Cerulean (Figure 5).

Such imaging studies can be subjective, depending on the field of cells examined, and are challenging to quantitate adequately. As such we approached a cell population analysis of ligand effects via a series of cell surface biotinylation studies (Figure 6). In cells induced to co-express the two receptors cell surface proteins were biotinylated and following challenge with various ligand combinations for $30 \mathrm{~min}$ the biotin was cleaved from proteins remaining at the cell surface. Those proteins that had become internalized were 'protected' from removal of the biotin and after capture by streptavidin were resolved by SDS-PAGE and detected by immunoblotting. Treatment with each of DAMGO, morphine or carbachol alone did not increase the 'protected' form of FLAG-M $_{3}$-Cerulean as detected by anti-FLAG immunoblotting (Figure 6A), whilst any increase in internalization of FLAG-M 3 -Cerulean produced by combinations of carbachol with either DAMGO or morphine failed to reach statistically significant levels (Figure 6A). By contrast, in anti-MOP receptor immunoblots although neither morphine nor carbachol in isolation produced internalization of MOP-YFP compared to vehicle (Figure 6B), as expected, DAMGO generated strong internalization (Figure 6B). Although the effect of DAMGO was not enhanced with co-addition of carbachol (Figure 6B), the co-addition of morphine and carbachol also resulted in substantial internalization (Figure 6B). 
Phorbol myristate acetate (PMA) is a broad spectrum activator of protein kinase $\mathrm{C}$ isoforms. As such we assessed whether direct activation of protein kinase $C$ would mimic the effect of carbachol. Regardless the induction of FLAG-M 3 -Cerulean expression, addition of a combination of morphine and PMA $(0.1 \mu \mathrm{M})$ was unable to enhance internalization of MOPYFP to levels beyond those produced by morphine alone (Figure 7). Epifluorescence microscopy experiments conducted with cells expressing both receptors confirmed these results observed in biotinylation protection assays, i.e. morphine plus PMA treatment do not promote MOP-YFP receptor endocytosis (Figure 8A). Previous studies on the facilitation of MOP-YFP receptor internalisation by co-activation of $5-\mathrm{HT}_{2 \mathrm{~A}}$ receptors demonstrated the participation of $\mathrm{PKC}$ in this process by preventing this effect upon treatment with selective inhibitors of this kinase. Equivalent experiments were performed with cells co-expressing FLAG-M 3 -Cerulean and MOP-YFP receptors (Figure 8B and 8C); in this case, neither Ro31-8220 $(0.1 \mu \mathrm{M})$ nor chelerytrine $(1 \mu \mathrm{M})$ significantly inhibited MOP-YFP receptor internalisation promoted by morphine plus carbachol treatment.

\subsection{MOP and M3 receptor interaction studies}

Epifluorescence microsocopy images obtained from cells expressing MOP-YFP and FLAG$\mathrm{M}_{3}$-Cerulean receptors after 24 hours of doxycycline induction revealed a co-distribution of both receptors in those cell compartments where they are expressed, principally in the plasma membrane. This cellular co-localisation prompted us to further investigate whether MOP and $\mathrm{M}_{3}$ are interacting to each other constituting receptor heterocomplexes. Coimmunoprecipitation experiments were conducted by using anti-MOP receptor as immunoprecipitating antibody in cell lysates in order to acquire samples enriched in MOPYFP receptors. Subsequently, these samples were subjected to SDS-PAGE electrophoresis and the resulted immunoblots processed with anti-FLAG antibody. As anticipated, samples 
from cells not treated with doxycycline and therefore not expressing FLAG-M 3 -Cerulean receptors resulted in a complete absence of specific immunoreactivity signal at the expected size for FLAG-M3-Cerulean receptor (Figure 9A, lane Ø) excluding then the possibility of any artifactual result. However, similar results were observed after 24 hours of doxycycline induction, i.e. no specific signal was observed in blots corresponding to immunoprecipitated samples obtained from cells co-expressing both receptors (Figure 9 A, lane 24). The presence of MOP-YFP and FLAG-M3-Cerulean receptors in these samples was controlled by analysing the specific immunoreactivity of MOP and FLAG antibodies in blots obtained from cell lysates prior to immunoprecipitation (Figure 9 A, lower panels). Doxycycline time-course experiments were carried out in order to evaluate the potential effect of the inducible receptor (FLAG-M 3 -Cerulean) period of expression on the formation of heterocomplexes with the constitutively expressed receptor (MOP-YFP). Indeed, upon 96 hours of doxycycline treatment a clear and specific band corresponding to FLAG-M $\mathrm{M}_{3}-$ Cerulean size was observed in blots obtained from immunoprecipitated samples (Figure 9A, lane 96). Internalisation experiments conducted by both fluorescence microscopy and biotinylation protection assay (Figures 5 and 6 respectively) showed that MOP-YFP receptor endocytosis was not accompanied by FLAG-M 3 -Cerulean receptor either after stimulation of MOP receptors alone, i.e. DAMGO treatment or both receptors concurrently, i.e. DAMGO plus carbachol and morphine plus carbachol treatments. Cells used for those experiments were induced for 24 hours with doxycycline to get FLAG-M3-Cerulean receptors expressed and as described above at this time point there is not an interaction between both receptors. Therefore, cells induced to express FLAG-M 3 -Cerulean receptors for up to 96 hours were treated during 30 minutes with these drugs that promote MOP-YFP receptor internalisation, i.e. DAMGO, DAMGO plus carbachol and morphine plus carbachol as well as vehicle as a control. After treatments, cell lysates were obtained to be immunoprecipitated with anti-MOP antibody and 
subsequently processed by Western blotting with anti-FLAG antibody (Figure 9B). Blots obtained with immunoprecipitates showed a specific band corresponding to FLAG-M 3 Cerulean receptors in the four experimental conditions considered, although the signal was substantially weaker in samples originated from cells treated with DAMGO alone (Figure 9B, lane D). The reason of that divergence was not possible disparities in the expression levels of both receptors among the different treatment groups since immunoblots obtained with cell lysates prior to immunprecipitation showed no substantial differences in signals obtained with either anti-FLAG as anti-MOP antibodies (Figure 9B, lower panels). Equivalent experiments were conducted in parallel by fluorescence microscopy to evaluate the endocytosis of both receptors under these experimental conditions. After 30 minutes of treatment, vehicle cells show both receptors predominantly at the plasma membrane (Figure 9C, Ø); in contrast, MOP-YFP receptors in cells treated with DAMGO presented a robust internalisation whereas FLAG-M ${ }_{3}-$ Cerulean receptors remained at the cell surface (Figure 9C, D). Finally, concurrent treatment using either DAMGO plus carbachol as morphine plus carbachol, resulted in the formation of endocytosis vesicles for both receptors (Figure 9C, DC and MC). A detailed observation of the microscopy fluorescence images corresponding to these experimental conditions where both FLAG-M3-Cerulean and MOP-YFP receptors endocytosed indicates that the majority of vesicles containing either receptor do not coincide spatially in intracellular compartments (Figure 9C, DC and MC). In order to further explore more accurately this issue, co-localization analysis of both fluorescent signals were conducted by confocal microscopy in cells induced to express FLAG-M3-Cerulean receptors with doxycycline for either 24 or 96 hours and subsequently treated with combinations of DAMGO plus carbachol or morphine plus carbachol to promote the internalization of both co-expressed receptors. As already observed in biotinylation protection assays (Figure 6), both agonist combinations resulted in a robust internalization of MOP-YFP receptors visualized as a YFP 
fluorescent signal in form of punctuate vesicles distributed throughout plasma membrane and cytosolic structures in cells treated for 24 hours with doxycycline to induce the expression of FLAG-M3-Cerulean receptors (Figure 10, 24 hours DOX, DC and MC). Equivalent microscopic fields illuminated to make visible FLAG-M3-Cerulean receptors display a fluorescent signal distribution substantially divergent, particularly in intracellular compartments where the presence of FLAG-M3-Cerulean receptors in form of endocytic vesicles are notably reduced in comparison to MOP-YFP receptors (Figure 10, 24 hours DOX, DC and MC). Pearson's correlation analysis to determine the co-localization degree between both Cerulean and YFP images resulted in reduced coefficient values in selected cytosolic regions of cells treated with DAMGO plus carbachol and morphine plus carbachol, i.e. $r=0.223$ and $r=0.248$ respectively (Figure 10, 24 hours DOX, DC and MC). On the other hand, coefficient correlation values obtained in cellular regions corresponding to the plasma membrane from the same microscopic fields resulted markedly higher, $r=0.642$ and $r$ $=0.579$ respectively, and comparable to the one determined in the plasma membrane of control cells treated with vehicle, i.e. $r=0.654$ (Figure 10, 24 hours DOX). Paralleled experiments were carried out with cells induced to express FLAG-M3-Cerulean receptors for 96 hours (Figure 10, 96 hours DOX); under these experimental conditions, treatment with either DAMGO or morphine both of them in combination with carbachol for 30 minutes led to FLAG-M3-Cerulean and MOP-YFP receptor internalization (Figure 9C, DC and MC), being in this case FLAG-M3-Cerulean receptor endocytosis more manifest in concofocal microscopy images than in equivalent conditions from cells treated with doxycycline for 24 hours (Figure 10, 24 hours and 96 hours, DC and MC). However, although the presence of FLAG-M3-Cerulean receptor in cytosolic compartments in form of punctuate structures was at a similar extent of the ones observed for MOP-YFP receptors, both fluorescent signal distributions were predominantly different when overlapping selected regions from the same 
microscopy field (Figure 10, 96 hours, DC and MC). The correlation coefficients obtained from images including endocytic vesicles corresponding to both receptors in cells treated either with DAMGO plus carbachol or morphine plus carbachol were $r=0.368$ and $r=0.372$ respectively. These coefficient values were substantially lower than the ones determined in areas corresponding to the plasma membrane from the same cells, i.e. $r=0.731$ and $r=0.719$ respectively, that were comparable to the correlation coefficient observed in the plasma membrane of control cells treated with vehicle, i.e. $r=0.764$ (Figure 10, 96 hours, DC and MC). Therefore, these data indicate that after 96 hours of doxycycline treatment FLAG-M3Cerulean and MOP-YFP receptors co-localize essentially at the plasma membrane level where their concurrent activation by selective agonists, i.e. DAMGO or morphine in combination with carbachol, led to their simultaneous internalization predominantly within separate endocytic vesicles.

\subsection{Quantitative analysis of MOP-YFP receptor endocytosis by fluorescence microscopy in living cells}

The formation of endocytic vesicles upon receptor activation by agonist compounds constitutes a biological response susceptible to be measured and evaluated in terms of the magnitude, i.e. number of endosomes, as well as the kinetics of this process, i.e. half time to reach the maximal effect. We have recently developed an image analysis tool to quantitatively assess MOP-YFP receptor internalization following agonist stimulation in images obtained from living cells by fluorescence microscopy [14]. In order to investigate the potential effect of FLAG-M3-Cerulean and MOP-YFP receptor interactions on MOP-YFP receptor endocytosis promoted by agonists, cells were treated with doxycycline for different periods ranging from 24 to 120 hours with an interval of 24 hours between each time point. Afterwards, cells were treated with DAMGO or morphine plus carbachol during 15 minutes 
and images from different planes through the Z-axis were acquired at 1-minute intervals. Cells not treated with doxycycline, and therefore not expressing FLAG-M3-Cerulean receptors, exhibited MOP-YFP receptor endocytosis when challenged with either DAMGO or combined morphine plus carbachol, evidencing that the involvement of M3 receptors endogenously expressed in Flp-In T-Rex 293 is sufficient to facilitate MOP-YFP receptor internalization by morphine (Table 2). When comparing the endocytosis response elicited by M3 and MOP-YFP receptor co-activation with the equivalent one observed upon direct activation of MOP-YFP receptor with DAMGO, morphine plus carbachol response resulted significantly lower $(17.82 \pm 2.79$ versus $35.11 \pm 3.88$ vesicles per cell, $t$-test $\mathrm{P}=0.024)$ and less rapid endocytosis $(7.72 \pm 0.69$ versus $4.40 \pm 0.32$ half time in minutes, t-test $\mathrm{P}=0.012)$ (Table 2). On the other hand and regardless the period of doxycycline treatment to induce its expression, the presence of FLAG-M3-Cerulean receptor did not significantly modify MOPYFP receptor endocytosis parameters observed in morphine plus carbachol treatments in terms of efficiency and half time to reach this maximal response (Table 2). In a different manner, co-expression with FLAG-M3-Cerulean resulted in a significant reduction of the maximal response in form of number of vesicles per cell containing MOP-YFP receptors upon treatment with DAMGO being the magnitude of this reduction similar across the different time points of doxycycline treatment (Table 2). However, this effect of FLAG-M3-Cerulean receptors on the maximal endocytic response of MOP-YFP receptor elicited by DAMGO was not accompanied by a significant change in the kinetic properties of the process (Table 2).

\section{Discussion}

Previous investigations on different molecular pharmacology aspects of MOP receptors conducted in heterologous expression models have revealed an evident functional selectivity in relation to the initiation of endocytosis processes in response to agonist binding [4]. In this 
sense, morphine constitutes one of the most paradigmatic examples due to its inability to promote MOP receptor internalisation in the majority of the cellular expression systems where it has been assayed [5]. However, this lack of efficacy in promoting receptor internalisation is not accompanied by an equivalent deficiency in other functional responses, i.e. coupling to $\mathrm{G}_{\mathrm{i} / \mathrm{o}}$ proteins, assessed by intracellular second messenger determinations such as cyclic AMP levels or incorporation of radioactive non-hydrolysable forms of guanine nucleotides (GTP $\gamma \mathrm{S})$. Although the molecular and cellular mechanisms underlying the disparity observed for morphine when compared to other MOP receptor agonists are not completely elucidated, substantial efforts and advances have been achieved during the last years to solve this scientific question [10]. Actually, the inability of morphine to endocytose MOP receptors upon activation may be overcome since under particular circumstances the internalisation of MOP receptors by morphine is possible, essentially by overexpression of accessory proteins involved in G-protein coupled receptor endocytosis mediated by agonist binding, principally GRK2 and $\beta$-arrestin2 among others $[5,11,12]$. We recently described that the co-activation of either $5-\mathrm{HT}_{2 \mathrm{~A}}$ or $5-\mathrm{HT}_{2 \mathrm{C}}$ serotonin receptor subtypes facilitates the endocytosis of MOP receptors promoted by morphine when co-expressed in Flp- $\operatorname{In}^{\mathrm{TM}} \mathrm{T}$ $\mathrm{REx}^{\mathrm{TM}} 293$ cells $[13,14]$. In the case of $5-\mathrm{HT}_{2 \mathrm{~A}}$ receptors, we demonstrated that this facilitation is dependent on receptor coupling to $G \alpha_{q / 11}$ subunits and subsequent PKC activation. As a consequence of their high degree of structural homology [25], 5- $\mathrm{HT}_{2 \mathrm{~A}}$ and 5$\mathrm{HT}_{2 \mathrm{C}}$ receptors share their functional pharmacological profile in terms of the initiation of signalling cascades by coupling preferentially to $G \alpha_{\mathrm{q} / 11}$ proteins and successive activation of different phospholypases and intracellular calcium mobilisation pathways. In the present study we have extended these investigations by examining whether a different $\mathrm{G}_{\mathrm{q} / 11}$ coupled receptor emulates that effect observed with $5-\mathrm{HT}_{2}$ receptor subtypes. Therefore, the muscarinic M3 acetylcholine receptor was chosen for this purpose based mainly on two 
reasons; firstly, both M3 and MOP receptors are found in the same cellular population in native neural tissue, as is the case of adrenergic neurons from the locus coeruleous. Secondly, previous investigations performed in locus coeruleus neurons demonstrated a functional interaction between M3 and MOP endogenous receptors consisting in the increased acute desensitisation of the opioid receptor in response to morphine when $\mathrm{PKC}$ is activated either directly by phorbol esters or indirectly through M3 receptors $[18,19]$. With that in mind, a Flp-In ${ }^{\mathrm{TM}} \mathrm{T}-\mathrm{REx}^{\mathrm{TM}} 293$ cell line harbouring the gene encoding for FLAG-M3-Cerulean receptor in the inducible locus was generated. The pharmacological characterisation of this modified version of the human M3 receptor resulted in similar parameters to these previously described from studies conducted with the wild type receptor heterologously expressed in cell lines, either in terms of $\left[{ }^{3} \mathrm{H}\right] \mathrm{QNB}$ constant affinity [26] or carbachol potency to generate inositol phosphate accumulation response [27]. Additionally, it was detected specific $\left[{ }^{3} \mathrm{H}\right] \mathrm{QNB}$ binding sites together with functional carbachol responses in inositol phosphates and calcium mobilisation assays in the absence on FLAG-M3-Cerulean receptor expression corroborating, therefore, the endogenous expression of muscarinic acetylcholine receptors in HEK 293 cells already characterized as the M3 subtype [24].

We formerly described that MOP-YFP receptors heterologously expressed in Flp-In T-REx HEK293 cells were functional in $\left[{ }^{35} \mathrm{~S}\right] \mathrm{GTP} \gamma \mathrm{S}$ binding assays [13] when stimulated with selective agonists such as DAMGO and morphine, presenting both agonists an equivalent potency and efficacy for MOP-YFP receptors in that functional assay. However, the main difference between both agonists was found after sustained stimulation of the receptors, i.e., whereas DAMGO pre-treatment of cells for a period up to 4 hours resulted in a significant lost of potency of this agonist in $\left[{ }^{35} \mathrm{~S}\right] \mathrm{GTP} \gamma \mathrm{S}$ binding assays, morphine was ineffective in promoting this desensitisation in parallel experiments. Nevertheless, the concomitant stimulation of serotonin 5-HT2A co-expressed with MOP-YFP receptors facilitated their 
desensitisation by morphine after continued treatment. Equivalent results have been observed in relation to the loss of potency of morphine when FLAG-M3-Cerulean and MOP-YFP receptors were continuously activated concurrently with carbachol and morphine respectively. On the contrary, pre-treatment of cells with carbachol at different time points up to 4 hours was devoid of any significant effect on morphine potency in $\left[{ }^{35} \mathrm{~S}\right] \mathrm{GTP} \gamma \mathrm{S}$ binding assays excluding, therefore, an heterologous desensitisation of MOP-YFP receptors mediated by M3 receptor activation. That lost of potency of morphine in $\left[{ }^{35} \mathrm{~S}\right] \mathrm{GTP} \gamma \mathrm{S}$ binding assays in samples from cells pre-treated with morphine plus carbachol was accompanied by a significant down regulation of MOP receptors determined by specific $\left[{ }^{3} \mathrm{H}\right]$ diprenorphine binding sites, particularly after 2 hours of pre-treatment. This result also emulates the effects observed earlier in equivalent experiments conducted with cells co-expressing $5-\mathrm{HT}_{2 \mathrm{~A}}$ and MOP receptors [13].

In relation to the facilitation of MOP-YFP receptor internalisation by morphine upon the concurrent activation of FLAG-M3-Cerulean receptors with carbachol, both epifluorescence microscopy experiments conducted with living cells and biotinylation protection assays evidenced the endocytosis of MOP receptors apparently at the same extent than the observed when using DAMGO as activating agonist. However, a detailed examination of both endocytosis processes performed by using an image analysis method recently described in our laboratory [14] revealed a significant difference between these two experimental situations in terms of the kinetics of the process. Morphine plus carbachol treatment mediated internalisation of MOP-YFP receptors is notably slower that the equivalent observed upon DAMGO treatment, suggesting a different molecular machinery behind these cellular events. With respect the quantification of endocytosis as a pharmacological response, the number of endosomes per cell obtained when using DAMGO as agonist was about twice the value resulted from equivalent treatments using morphine plus carbachol to activate M3 muscarinic 
receptors endogenously expressed in Flp-In T-REx HEK293. Intriguingly, the expression of FLAG-M3-Cerulean receptors by doxycycline treatment promoted a substantial reduction of the endocytosis response evoked by DAMGO to a degree equivalent to the observed with morphine plus carbachol, being both responses comparable independently of the duration of the doxycycline treatment. The changes observed in the efficiency of the endocytosis response by DAMGO were not accompanied by a reduction in the velocity of the process since the kinetics of MOP-YFP internalisation remained unaffected throughout the different periods of doxycycline treatment. These results from quantitative endocystosis assays together with the fact that FLAG-M3-Cerulean receptor did not internalise either by stimulation with carbachol or in conjunction with MOP-YFP receptors, suggest a potential dominant negative effect of FLAG-M3-Cerulean over MOP-YFP receptors caused by protein-protein interactions that lead to the MOP-YFP receptor retention in the plasma membrane. Co-immunoprecipitation experiments demonstrated that FLAG-M3-Cerulean and MOP-YFP receptors form stable receptor heterocomplexes at the plasma membrane that are enriched through time, i.e., the longest is the period of doxycycline treatment the strongest is the co-immunoprecipitation signal obtained. This increase in the co-immunoprecipitation signal follows the increase of FLAG-M3-Cerulean receptor expression levels as visualised by Western blot analysis in equivalent periods of doxycycline treatment, suggesting a direct effect of the amount of FLAG-M3-Cerulean receptors in the formation of heteromers with MOP-YFP receptors. According to this result, one might assume that under longer periods of doxycycline induction the heteroreceptor complex is more consolidated and therefore, the potential effect on FLAGM3-Cerulean/MOP-YFP receptor trafficking more evident. Under these experimental conditions, i.e., 96 hours of receptor co-expression, the endocytosis of MOP-YFP receptors generated by DAMGO was not reduced in number of endosomes per cell in comparison with the one determined at 24 hours of doxycycline treatment. However, co-immunoprecipitation 
experiments performed with cells treated with doxycycline for 96 hours and stimulated with DAMGO resulted in a substantial reduction in co-immunoprecipitated receptors with regards equivalent samples from cells not treated with agonist. Similarly, internalising MOP-YFP receptors are not accompanied by FLAG-M3-Cerulean receptors suggesting that a major fraction of the opioid receptor abandons the heterocomplex in the plasma membrane once they are conducted to the endocytic pathways. During the course of our investigations, the endocytosis of FLAG-M3-Cerulean receptor in response to carbachol in the Flp-In T-REx HEK293 expression system was not detected either by epifluorescence microscopy or biotinylation protection assays in cells treated with doxycycline for 24 hours. Similarly and under the same experimental conditions, stimulation of the co-expressed MOP-YFP receptor with either DAMGO or morphine resulted ineffective in facilitating the internalisation of FLAG-M3-Cerulean receptors. However, when cells were induced to express muscarinc receptors for up to 96 hours in order to allow the formation of detectable receptor heteromers, treatment of these cells with agonists for both receptors, i.e. DAMGO plus carbachol or morphine plus carbachol, resulted in the formation of detectable endocytic vesicles corresponding to FLAG-M3-Cerulean and MOP-YFP receptors in fluorescent microscopy images. Intriguingly, a meticulous co-localization analysis conducted by confocal microscopy imaging revealed that endosomes containing FLAG-M3-Cerulean and MOP-YFP receptors were segregated in different pools throughout cytoplasmic compartments, at difference of the plasma membrane where both receptors presented a higher degree of spatial coincidence. This result, together with the fact that the strongest interaction between both receptors is detected at this experimental condition, suggests that heteromeric complexes are essentially allocated in the plasma membrane and excludes a direct involvement of this receptor-receptor interaction in the occurrence of FLAG-M3-Cerulean receptor internalization. One possible explanation for this trafficking dissociation could be the inclusion in endosomes of those 
receptors from the total population not engaged in heteromeric complexes. Actually, an important proportion of both receptors still remains at the plasma membrane when internalization of FLAG-M3-Cerulean and MOP-YFP receptors occurs. Otherwise, the reduction in co-immunoprecipitation signal when MOP-YFP is the only internalizing receptor could be indicative of a heteromer disruption upon the endocytosis initiated by agonist binding. Nevertheless, it seems to be necessary the prior formation of heteromeric complexes to get a substantial FLAG-M3-Cerulean receptor internalization.

Our results described herein in relation to firstly, the effect of FLAG-M3-Cerulean and MOPYFP heteromerization on the opioid receptor trafficking and secondly, the divergence in the endosome sorting in these conditions when both receptors internalize, are indicative of the temporal and dynamic character of this receptor-receptor interaction. Results from previous studies that examined the effects of receptor heteromerization on MOP internalisation are discrepant and depending on the receptor partner considered for the investigation. In this sense, an initial research conducted on MOP-DOP heteromers concluded that both receptors endocytose separately, being the putative heterodimer only at the plasma membrane and suggesting, therefore, that MOP-DOP heteromers are contact dimers rather than domain swapping heterocomplexes [28]. However, a more recent study on the endocytic and postendocytic fate of MOP, DOP and MOP-DOP heteromers comes into contradiction with that previous one since they described that MOP receptor adopts novel trafficking properties in the context of MOP-DOP heterocomplexes [29]. Another circumstance where MOP receptors are internalising separately from its partner is the case of MOP- $\alpha_{2 \mathrm{~A} A R}$ heteromer [30] where the interaction between both receptors was demonstrated by coimmunoprecipitation experiments when co-expressed in HEK 293 cells and adrenaline and DAMGO treatments facilitated only the endocytosis of their corresponding receptors, i.e. $\alpha_{2 \mathrm{~A}} \mathrm{AR}$ and MOP respectively. On the other hand, it seems there is not a correlation between 
co-internalization and modified signalling in heteromers where one of the receptors is MOP, as is the case of $\mathrm{MOP}$ and 5- $\mathrm{HT}_{1 \mathrm{~A}}$ receptor interactions [31]; when both receptors are expressed in HEK 293 cells, the activation of 5- $\mathrm{HT}_{1 \mathrm{~A}}$ receptors do not co-internalize the coexpressed MOP receptors and contrariwise. Moreover, there are also other circumstances where the interaction of MOP with other receptors led to modifications in the trafficking properties of any of the monomers. This is the case reported for the heteromerization of MOP and somatostatin sst $2 \mathrm{~A}$ receptors [32], the agonist stimulation of sst2A within the heteromer induced the internalisation of both receptors whereas DAMGO stimulation of MOP receptors in the heteromer promotes the phosphorylation and desensitization of both receptors but not the internalization of sst $2 \mathrm{~A}$ receptors. In a similar manner, the same group described that MOP and substance P NK1 receptor heteromerization did not change the ligand binding and signalling properties of these receptors, but it altered their internalization and resensitization profile [33]. Another case of asymmetric facilitation in the monomer internalization in heterocomplexes participated by MOP receptor is the one corresponding to MOP-mGluR5 heteromers [34] where DAMGO treatments induced a significant co-internalization of MOP and mGluR5 in cells expressing both receptors. Overall and taking into account all these former observations already described where MOP receptor is part of heteroreceptor complexes, it seems that the stability of FLAG-M3-Cerulean/MOP-YFP receptor heteromers is a transient attribute rather than a permanent one and depends on the cellular localization and state of activation of both receptors. Whether FLAG-M3-Cerulean and MOP-YFP receptors interact with each other at the earlier stages of the biosynthetic pathways or once they reach the cell surface in their final mature form constitutes an issue not explored in our current investigations. However, confocal microscopy images point to the plasma membrane as the cell compartment where both receptors are primarily located. In addition, the different mode of expression followed for each protomer, i.e. inducible versus permanent, leads us to 
conjecture that both receptors have higher chance to find to each other at the end of their synthesis and maturation than during the initial moments. This would further explain why robust signals after co-immunoprecipitation are obtained only after a longer period of expression of the M3 receptor, suggesting a possible gain of both heteromer stability and/or quantity following that period of receptor co-expression.

We have previously shown using pharmacological inhibitors that $\mathrm{PKC}$ activation can directly regulate the endocytosis of MOP receptor by morphine facilitated by $5-\mathrm{HT}_{2} \mathrm{~A}$ receptor stimulation [13]. In relation to M3 muscarinic receptors, it has been reported a pharmacological interaction with MOP receptors in locus coeruleus consisting in the enhancement of MOP receptor desensitisation mediated by PKC [18, 19]. Actually, similar effects were achieved by the direct activation of PKC using phorbol esters bypassing therefore, the activation of M3 receptors. Additional studies in vivo and in vitro have also demonstrated that tolerance after chronic morphine treatment is attenuated or reversed when PKC inhibitors are co-administered [35]. In our present results we have not observed any type of facilitation of MOP-YFP receptor endocytosis promoted by morphine when activating directly PKC with a phorbol ester, in agreement with the observations from transgenic mice expressing FLAG-MOP receptors in locus coeruleus where activators of PKC had no significant roles in MOP receptor endocytosis [19]. Furthermore, in our experimental model, the endocytosis of MOP receptors by morphine facilitated by M3 receptor co-activation was not reverted by treatment with two different PKC inhibitors, which indicates potential differences between the molecular mechanisms underlying the facilitation mediated by 5 $\mathrm{HT}_{2 \mathrm{~A}}$ with respect to $\mathrm{M} 3$ receptors.

\section{Conclusions}


In the present report we demonstrate that the activation of $\mathrm{M} 3$ muscarinic receptors, which couples preferentially to $\mathrm{G} \alpha_{\mathrm{q} / 11}$ proteins, facilitates the desensitisation, down-regulation and internalization of MOP receptors by morphine when both receptors are co-expressed in Flp-In T-REx HEK293 cells. Particularly, and in the case of the facilitation of MOP receptor endocytosis by morphine, this process is not dependent on the activation of PKC at difference of what was previously observed for 5- $\mathrm{HT}_{2 \mathrm{~A}}$ receptors. Fluorescence microscopy observations indicate that FLAG-M3-Cerulean and MOP-YFP receptors are mainly located in the plasma membrane where both receptors are prone to interact to each other constituting heterocomplexes. Furthermore, the formation of these heteromers seems to be dependent on time and the level of expression of FLAG-M3-Cerulean receptors. Although this proteinprotein interaction affects to some extent the endocytosis of MOP-YFP receptors in terms of the quantity of endosomes generated upon agonist activation, these heteromers are not present in endocytic vesicles when both receptors internalize either because the heteromer in the plasma membrane is disrupted or because a fraction of the total population of receptors not participating in the heteromer complex is the one that suffers internalization. Summarizing, M3 and MOP receptors present pharmacological interactions when co-expressed that are evidenced as alterations of some MOP receptor properties mediated by morphine binding. That pharmacological interaction is also accompanied by the formation of heteromers between both receptors with some consequences on MOP receptor trafficking. The dynamics associated to the stability of these receptor heterocomplexes in the plasma membrane might be indicative of the complexity of this type of protein-protein interaction. 


\section{Acknowledgements}

This study was supported by Biotechnology and Bioscience Research Council Grant BB/G0011200/1, Consejo Superior de Investigaciones Científicas, CSIC, Grant 20098I110 and Grant SAF2010-15663 from the Spanish Government (MINECO). 


\section{Table 1}

Desensitization studies in cells co-expressing FLAG-M3-Cerulean and MOP-YFP receptors.

Cells treated with doxycycline 24 hours prior the assay were incubated with morphine, carbachol or morphine plus carbachol at the specified concentrations during 30, 60, 120 and 240 min. The different values correspond to the mean \pm SEM of the results obtained from a number of independent experiments as indicated in brackets. (pEC50): Two-way ANOVA on the effect of Pre-treatment $F_{(2,30)}=12.42(\mathrm{P}=0.0001)$, Time $\mathrm{F}_{(4,30)}=4.86(\mathrm{P}=0.0038)$ and Pre-treatment/Time interaction $\mathrm{F}_{(8,30)}=3.01(\mathrm{P}=0.0132) .{ }^{*}$ Dunnett's Post-test comparing to not pre-treated P $<0.05$. $\left(\boldsymbol{E}_{\boldsymbol{m a x}}\right)$ : Two-way ANOVA on the effect of Pre-treatment $\mathrm{F}_{(2,30)}=$ $11.73(\mathrm{P}=0.0002)$, Time $\mathrm{F}_{(4,30)}=1.03(\mathrm{P}=0.4071)$ and Pre-treatment/Time interaction $\mathrm{F}_{(8,30)}$

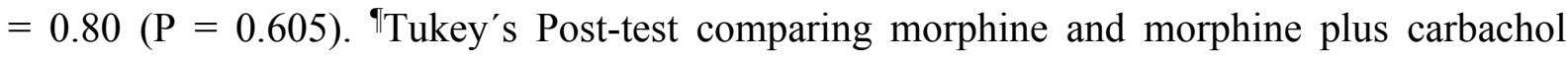
treatments $\mathrm{P}<0.05$.

\section{Table 2}

Quantitative analysis of MOP-YFP receptor endocytosis by fluorescence microscopy in living cells.

Cells were submitted to doxycycline treatment for different periods from 24 to 120 hours in order to co-express FLAG-M3-Cerulean and MOP-YFP receptors at different time lengths. Afterwards, cells were treated with either DAMGO or morphine + carbachol for 15 minutes and images were acquired by epifluorescence microscopy. Quantification of endocytosis was conducted by image analysis with Q-Endosomes algorithm (see Methods section). The different values correspond to the mean \pm SEM of the results obtained from a number of independent experiments as indicated in brackets. DAMGO treatment, $\left(\mathrm{t}_{1 / 2}\right)$ One-way ANOVA $\mathrm{P}=0.6113$. Morphine + carbachol treatment, $\left(\mathrm{t}_{1 / 2}\right)$ One-way ANOVA $\mathrm{P}=0.5067$. 
DAMGO treatment, $\left(E_{\max }\right)$ One-way ANOVA $\mathrm{P}=0.0065$. *Dunnett's Post-Test $\mathrm{P}<0.05$. Morphine + carbachol treatment, $\left(E_{\max }\right)$ One-way ANOVA $\mathrm{P}=0.9453 .{ }^{\natural}$ t-test $\mathrm{P}<0.05$ when comparing DAMGO and morphine + carbachol groups within a particular doxycycline treatment time point. 


\section{Figure Legends}

\section{Figure 1}

Generation of a FIp-In T-Rex 293 cell line harbouring FLAG-M3-Cerulean receptor in the inducible locus and permanently expressing MOP-YFP receptor.

A: Epifluorescence microscopy imaging of cells treated with doxycycline at $10 \mathrm{ng} \cdot \mathrm{mL}^{-1}$ for 24 hours. CFP channel column corresponds to a microscopic field illuminated with light settings to make visible Cerulean protein and YFP channel column to the same field illuminated to visualize yellow fluorescent protein. + DOX and - DOX panels indicate cells treated and not treated with doxycycline, respectively. B: Representative immunoblots obtained with membranes from cells expressing FLAG-M3-Cerulean and MOP-YFP receptors treated at different concentrations of doxycycline for 24 hours, as indicated above each lane, and resolved with an anti-FLAG antibody (upper panel) or an anti-MOP receptor antibody (lower panel). 105 indicates protein size in KDa. The panel at the bottom represents a semi-logarithm graph displaying the signal optical density (O.D.) values corresponding to each doxycycline concentration from an immunoblot resolved with anti-FLAG antibody.

\section{Figure 2}

Time course of FLAG-M3-Cerulean receptor expression induced by doxycycline treatment.

Representative immunoblots obtained with membranes from Flp-In T-Rex 293 cells expressing FLAG-M3-Cerulean and MOP-YFP receptors and treated with doxycycline at 10 ng. $\mathrm{mL}^{-1}$ for different periods as indicated in hours above each lane. The top panel corresponds to a blot resolved with an anti-FLAG antibody whereas the bottom panel corresponds to the equivalent blot resolved with an anti-MOP antibody. 105 indicates protein size in KDa. 


\section{Figure 3}

Pharmacological expression of FLAG-M3-Cerulean and MOP-YFP receptors and functional characterization of FLAG-M3-Cerulean receptors.

A: Graph plot displaying $\left[{ }^{3} \mathrm{H}\right] \mathrm{QNB}$ specific binding from a saturation binding assay performed with membranes from cells induced with doxycycline for $24 \mathrm{~h}$ to express FLAGM3-Cerulean receptors. B: Graph plot corresponding to $\left[{ }^{3} \mathrm{H}\right]$ diprenorphine specific binding from saturation binding assays performed with membranes from cells induced with doxycycline (filled symbols) and not treated with doxycycline (opened symbols). C: Carbachol dose-response curves displaying the generation of inositol 1,4,5-triphosphate (IP3) in cells induced with doxycycline for $24 \mathrm{~h}$ to express FLAG-M3-Cerulean receptors (filled symbols) and not treated with doxycycline (opened symbols). D: Carbachol dose-response curves corresponding to calcium mobilization experiments with cells induced with doxycycline for $24 \mathrm{~h}$ to express FLAG-M3-Cerulean receptors (filled symbols) and not treated with doxycycline (opened symbols).

\section{Figure 4}

Desensitisation and down-regulation studies on MOP-YFP receptors.

$\left[{ }^{35} \mathrm{~S}\right] \mathrm{GTP} \gamma \mathrm{S}$ binding assays in response to various concentrations of morphine with membranes from cells induced to express FLAG-M3-Cerulean receptors for 24 hours and treated with morphine at $10 \mu \mathrm{M}(\mathbf{A})$, carbachol at $1 \mathrm{mM}(\mathbf{B})$, and morphine plus carbachol (C), for different periods as indicated in each graph. D: Variation of binding sites determined at a saturating concentration of $\left[{ }^{3} \mathrm{H}\right]$ diprenorphine in membranes from cells induced to express FLAG-M3-Cerulean receptors for 24 hours and treated with morphine $(10 \mu \mathrm{M})$ or morphine $(10 \mu \mathrm{M})$ plus carbachol $(1 \mathrm{mM})$ for different times. 


\section{Figure 5}

Internalization assays by fluorescence microscopy with living cells.

Cells induced to express FLAG-M3-Cerulean receptors were treated with DAMGO $(10 \mu \mathrm{M})$, morphine $(10 \mu \mathrm{M})$, carbachol $(1 \mathrm{mM})$ or a combination of morphine plus carbachol, and images were acquired every $3 \mathrm{~min}$ during $30 \mathrm{~min}$. Pictures show images corresponding to the starting (00:00) and the end point (30:00) of the indicated agonist treatments from the same microscopic field illuminated to visualize MOP-YFP (MOP-YFP) or FLAG-M3-Cerulean (M3Cerulean) receptors.

\section{Figure 6}

\section{Internalization studies by biotinylation protection assays.}

Cells induced to express FLAG-M3-Cerulean receptors were biotinylated and subsequently treated for 30 min with DAMGO $(10 \mu \mathrm{M})$, morphine $(10 \mu \mathrm{M})$, carbachol $(1 \mathrm{mM})$, DAMGO plus carbachol (DC), morphine plus carbachol (MC) or vehicle (NT). After agonist treatment and biotin cleavage, cell lysates were immunoprecipitated with streptavidin and processed by Western blot analysis. A: Image corresponding to a representative immunoblot resolved with an anti-FLAG antibody. Bar graph displays the mean \pm SEM of the optical density measured from immunoblots of at least three independent experiments compared to the intensity signal value obtained with not treated $(\mathrm{NT})$ cells. One-way ANOVA, $\mathrm{P}=0.1659$. B: Image corresponding to a representative immunoblot resolved with an anti-MOP receptor antibody. Bar graph displays the mean \pm SEM of the optical density corresponding to the different experimental conditions measured from immunoblots corresponding to at least three independent experiments compared to the intensity signal value obtained with not treated (NT) cells. One-way ANOVA, $\mathrm{P}<0.0001 .{ }^{*}$ Dunnett's post hoc test, $\mathrm{P}<0.0001$. In both 
cases, $100 \%$ corresponds to control cells biotinylated and not submitted to cleavage and STRIP to biotinylated cells not treated with agonist drugs and processed for biotin cleavage.

\section{Figure 7}

Analysis of the effect of direct activation of PKC on MOP-YFP receptor internalization by biotinylation protection assays.

Biotinylated cells were treated with DAMGO $(10 \mu \mathrm{M})$, morphine $(10 \mu \mathrm{M})$, morphine plus PMA $(0.1 \mu \mathrm{M})$, morphine plus carbachol $(1 \mathrm{mM})$ or vehicle $(\mathrm{NT})$ for $30 \mathrm{~min}$ and subsequently submitted for biotin cleavage. Afterwards, cell lysates were immunoprecipitated with straptividine and samples processed by Western blot with an anti-MOP receptor antibody. Upper image shows a representative immunoblot where $100 \%$ corresponds to samples from cells biotinylated and submitted to neither cleavage nor agonist treatments, STRIP to biotinylated cells not treated with agonist drugs and processed for cleavage and + DOX indicates samples from cells treated with doxycycline for $24 \mathrm{~h}$ to induce the expression of FLAG-M3-Cerulean receptors. Lower bar graph represents the mean \pm SEM of the optical density corresponding to the different experimental conditions measured from immunoblots corresponding to at least three independent experiments and compared to the intensity signal value obtained with not treated $(\mathrm{NT})$ cells. One-way ANOVA, $\mathrm{P}<0.0001 .{ }^{*}$ Dunnett's post hoc test, $\mathrm{P}<0.0001$.

\section{Figure 8}

Effect of PKC direct activation or inhibition on MOP-YFP receptor internalization promoted by morphine.

Epifluorescence microscopy images taken from living cells showing MOP-YFP receptors before (00:00) and after (30:00) $30 \mathrm{~min}$ of the following drug treatments: morphine $(10 \mu \mathrm{M})$ 
plus PMA $(0.1 \mu \mathrm{M}) \mathbf{( A )}$, morphine plus carbachol $(1 \mathrm{mM})$ in concurrence with Ro31-8220 $(0.1 \mu \mathrm{M})(\mathbf{B})$ and morphine plus carbachol in concurrence with chelerytrine $(1 \mu \mathrm{M})(\mathbf{C})$. Cells were treated with doxycycline for $24 \mathrm{~h}$ prior to the experiment.

\section{Figure 9}

Effect of FLAG-M3-Cerulean and MOP-YFP receptor heteromerization on the internalization promoted by agonist stimulation.

A: Lysates from cells induced to express FLAG-M3-Cerulean receptors with doxycycline for different periods $(24,48,72$ and $96 \mathrm{~h})$ were immunoprecipitated with an anti-MOP receptor antibody $(\alpha \mathrm{MOP})$ and processed for Western blot analysis with anti-FLAG antibody $(\alpha$ FLAG). Upper panel shows a representative immunoblot obtained with these samples. Lower panels correspond to immunoblots from cell lysates before immunprecipitation resolved with either anti-FLAG ( $\alpha$ FLAG) or anti-MOP ( $\alpha$ MOP) antibodies to monitor FLAG-M3-Cerulean and MOP-YFP receptor expression in these cells. $\varnothing$ are samples from cells not treated with doxycycline. Protein sizes are indicated in KDa. B: Cells treated for 96 $\mathrm{h}$ with doxycycline were treated with DAMGO $(10 \mu \mathrm{M})(\mathrm{D})$, DAMGO plus carbachol $(1 \mathrm{mM})$ (DC), morphine $(10 \mu \mathrm{M})$ plus carbachol (MC) or vehicle $(\varnothing)$ for $30 \mathrm{~min}$ and subsequently cell lysates were immunoprecipitated with an anti-MOP receptor antibody and analysed by Western blot with anti-FLAG antibody (upper panel). Lower panels correspond to immunoblots resolved with either anti-FLAG or anti-MOP receptor antibodies to confirm the presence of FLAG-M3-Cerulean and MOP-YFP receptors in the original cell lysates. C: Epifluorescence microscopy images obtained from cells illuminated to simultaneously visualize FLAG-M3-Cerulean and MOP-YFP receptors (M3Cerulean and MOPYFP respectively) after $30 \mathrm{~min}$ of treatment with DAMGO $(10 \mu \mathrm{M})$, DAMGO plus carbachol 
$(1 \mathrm{mM})$, morphine $(10 \mu \mathrm{M})$ plus carbachol or vehicle $(\varnothing)$. Cells were treated with doxycycline for $96 \mathrm{~h}$ prior to the experiment.

\section{Figure 10}

Analysis of the subcellular co-localization of FLAG-M3-Cerulean and MOP-YFP receptors.

Fluorescence confocal microscopy images corresponding to cells from the same microscopic field treated with doxycycline for $24 \mathrm{~h}$ or $96 \mathrm{~h}$ and showing both FLAG-M3-Cerulean receptors (left column) and MOP-YFP receptors (middle column). Prior to image acquisition, cells were treated for 30 min with DAMGO plus carbachol $(1 \mathrm{mM})(\mathrm{DC})$, morphine $(10 \mu \mathrm{M})$ plus carbachol $(\mathrm{MC})$ or vehicle $(\varnothing)$. Yellow frames in each picture indicate these selected areas corresponding to either plasma membrane $(\mathrm{pm})$ or cytosolic regions $(\mathrm{c})$ where co-localization image analysis was performed. Right column panels show in detail merged FLAG-M3Cerulean (red) and MOP-YFP (green) images corresponding to the different selected areas. Overlapping Pearson's correlation coefficient (r) determined in each case is indicated at the bottom of each panel. 


\section{References}

[1] S. Ferre, V. Casado, L.A. Devi, M. Filizola, R. Jockers, M.J. Lohse, G. Milligan, J.P. Pin, X. Guitart, G protein-coupled receptor oligomerization revisited: functional and pharmacological perspectives, Pharmacol Rev, 66 (2014) 413-434.

[2] G. Milligan, The prevalence, maintenance, and relevance of G protein-coupled receptor oligomerization, Mol Pharmacol, 84 (2013) 158-169.

[3] J.D. Urban, W.P. Clarke, M. von Zastrow, D.E. Nichols, B. Kobilka, H. Weinstein, J.A. Javitch, B.L. Roth, A. Christopoulos, P.M. Sexton, K.J. Miller, M. Spedding, R.B. Mailman, Functional selectivity and classical concepts of quantitative pharmacology, J Pharmacol Exp Ther, 320 (2007) 1-13.

[4] K.M. Raehal, C.L. Schmid, C.E. Groer, L.M. Bohn, Functional selectivity at the muopioid receptor: implications for understanding opioid analgesia and tolerance, Pharmacol Rev, 63 (2011) 1001-1019.

[5] J.F. Lopez-Gimenez, G. Milligan, Opioid regulation of mu receptor internalisation: relevance to the development of tolerance and dependence, CNS Neurol Disord Drug Targets, 9 (2010) 616-626.

[6] J.L. Whistler, Examining the role of mu opioid receptor endocytosis in the beneficial and side-effects of prolonged opioid use: from a symposium on new concepts in mu-opioid pharmacology, Drug Alcohol Depend, 121 (2012) 189-204. 
[7] L. He, J.L. Whistler, An opiate cocktail that reduces morphine tolerance and dependence, Curr Biol, 15 (2005) 1028-1033.

[8] L. He, J. Fong, M. von Zastrow, J.L. Whistler, Regulation of opioid receptor trafficking and morphine tolerance by receptor oligomerization, Cell, 108 (2002) 271-282.

[9] J.A. Kim, S. Bartlett, L. He, C.K. Nielsen, A.M. Chang, V. Kharazia, M. Waldhoer, C.J. Ou, S. Taylor, M. Ferwerda, D. Cado, J.L. Whistler, Morphine-induced receptor endocytosis in a novel knockin mouse reduces tolerance and dependence, Curr Biol, 18 (2008) 129-135.

[10] J.T. Williams, S.L. Ingram, G. Henderson, C. Chavkin, M. von Zastrow, S. Schulz, T. Koch, C.J. Evans, M.J. Christie, Regulation of mu-opioid receptors: desensitization, phosphorylation, internalization, and tolerance, Pharmacol Rev, 65 (2013) 223-254.

[11] J. Zhang, S.S. Ferguson, L.S. Barak, S.R. Bodduluri, S.A. Laporte, P.Y. Law, M.G. Caron, Role for $\mathrm{G}$ protein-coupled receptor kinase in agonist-specific regulation of mu-opioid receptor responsiveness, Proc Natl Acad Sci U S A, 95 (1998) 7157-7162.

[12] J.L. Whistler, M. von Zastrow, Morphine-activated opioid receptors elude desensitization by beta-arrestin, Proc Natl Acad Sci U S A, 95 (1998) 9914-9919.

[13] J.F. Lopez-Gimenez, M.T. Vilaro, G. Milligan, Morphine desensitization, internalization, and down-regulation of the mu opioid receptor is facilitated by serotonin 5hydroxytryptamine2A receptor coactivation, Mol Pharmacol, 74 (2008) 1278-1291. 
[14] V.M. Campa, A. Capilla, M.J. Varela, A.M. de la Rocha, J.C. Fernandez-Troyano, R.B. Barreiro, J.F. Lopez-Gimenez, Endocytosis as a biological response in receptor pharmacology: evaluation by fluorescence microscopy, PLoS One, 10 (2015) e0122604.

[15] H.A. Baghdoyan, V.J. Mallios, R.B. Duckrow, D.C. Mash, Localization of muscarinic receptor subtypes in brain stem areas regulating sleep, Neuroreport, 5 (1994) 1631-1634.

[16] A. Tempel, R.S. Zukin, Neuroanatomical patterns of the mu, delta, and kappa opioid receptors of rat brain as determined by quantitative in vitro autoradiography, Proc Natl Acad Sci U S A, 84 (1987) 4308-4312.

[17] E. Erbs, L. Faget, G. Scherrer, A. Matifas, D. Filliol, J.L. Vonesch, M. Koch, P. Kessler, D. Hentsch, M.C. Birling, M. Koutsourakis, L. Vasseur, P. Veinante, B.L. Kieffer, D. Massotte, A mu-delta opioid receptor brain atlas reveals neuronal co-occurrence in subcortical networks, Brain Struct Funct, 220 (2015) 677-702.

[18] C.P. Bailey, E. Kelly, G. Henderson, Protein kinase C activation enhances morphineinduced rapid desensitization of mu-opioid receptors in mature rat locus ceruleus neurons, Mol Pharmacol, 66 (2004) 1592-1598.

[19] S. Arttamangkul, W. Birdsong, J.T. Williams, Does PKC activation increase the homologous desensitization of mu opioid receptors?, Br J Pharmacol, 172 (2015) 583-592.

[20] E. Alvarez-Curto, R.J. Ward, J.D. Pediani, G. Milligan, Ligand regulation of the quaternary organization of cell surface M3 muscarinic acetylcholine receptors analyzed by 
fluorescence resonance energy transfer (FRET) imaging and homogeneous time-resolved FRET, J Biol Chem, 285 (2010) 23318-23330.

[21] R.J. Ward, E. Alvarez-Curto, G. Milligan, Using the Flp-In T-Rex system to regulate GPCR expression, Methods Mol Biol, 746 (2011) 21-37.

[22] M. Canals, G. Milligan, Constitutive activity of the cannabinoid CB1 receptor regulates the function of co-expressed Mu opioid receptors, J Biol Chem, 283 (2008) 11424-11434.

[23] S. Bolte, F.P. Cordelieres, A guided tour into subcellular colocalization analysis in light microscopy, Journal of microscopy, 224 (2006) 213-232.

[24] J. Luo, J.M. Busillo, J.L. Benovic, M3 muscarinic acetylcholine receptor-mediated signaling is regulated by distinct mechanisms, Mol Pharmacol, 74 (2008) 338-347.

[25] J.E. Leysen, 5-HT2 receptors, Curr Drug Targets CNS Neurol Disord, 3 (2004) 11-26.

[26] E.G. Peralta, A. Ashkenazi, J.W. Winslow, D.H. Smith, J. Ramachandran, D.J. Capon, Distinct primary structures, ligand-binding properties and tissue-specific expression of four human muscarinic acetylcholine receptors, EMBO J, 6 (1987) 3923-3929.

[27] M.H. Richards, P.L. van Giersbergen, Human muscarinic receptors expressed in A9L and CHO cells: activation by full and partial agonists, Br J Pharmacol, 114 (1995) 12411249 
[28] P.Y. Law, L.J. Erickson-Herbrandson, Q.Q. Zha, J. Solberg, J. Chu, A. Sarre, H.H. Loh, Heterodimerization of mu- and delta-opioid receptors occurs at the cell surface only and requires receptor-G protein interactions, J Biol Chem, 280 (2005) 11152-11164.

[29] L. Milan-Lobo, J.L. Whistler, Heteromerization of the mu- and delta-opioid receptors produces ligand-biased antagonism and alters mu-receptor trafficking, J Pharmacol Exp Ther, 337 (2011) 868-875.

[30] Y.Q. Zhang, L.E. Limbird, Hetero-oligomers of alpha2A-adrenergic and mu-opioid receptors do not lead to transactivation of G-proteins or altered endocytosis profiles, Biochem Soc Trans, 32 (2004) 856-860.

[31] D. Cussac, I. Rauly-Lestienne, P. Heusler, F. Finana, C. Cathala, S. Bernois, L. De Vries, mu-opioid and 5-HT1A receptors heterodimerize and show signalling crosstalk via G protein and MAP-kinase pathways, Cell Signal, 24 (2012) 1648-1657.

[32] M. Pfeiffer, T. Koch, H. Schroder, M. Laugsch, V. Hollt, S. Schulz, Heterodimerization of somatostatin and opioid receptors cross-modulates phosphorylation, internalization, and desensitization, J Biol Chem, 277 (2002) 19762-19772.

[33] M. Pfeiffer, S. Kirscht, R. Stumm, T. Koch, D. Wu, M. Laugsch, H. Schroder, V. Hollt, S. Schulz, Heterodimerization of substance $\mathrm{P}$ and mu-opioid receptors regulates receptor trafficking and resensitization, J Biol Chem, 278 (2003) 51630-51637. 
[34] H. Schroder, D.F. Wu, A. Seifert, M. Rankovic, S. Schulz, V. Hollt, T. Koch, Allosteric modulation of metabotropic glutamate receptor 5 affects phosphorylation, internalization, and desensitization of the micro-opioid receptor, Neuropharmacology, 56 (2009) 768-778.

[35] C.P. Bailey, F.L. Smith, E. Kelly, W.L. Dewey, G. Henderson, How important is protein kinase $\mathrm{C}$ in mu-opioid receptor desensitization and morphine tolerance?, Trends Pharmacol Sci, 27 (2006) 558-565. 
Table 1.

\begin{tabular}{|c|c|c|c|c|c|c|}
\hline \multirow{4}{*}{$\mathrm{pEC}_{50}$} & Not pre-treated & $30 \mathrm{~min}$ & $60 \mathrm{~min}$ & $120 \mathrm{~min}$ & $240 \mathrm{~min}$ & Pre-treatment \\
\hline & $7.62 \pm 0.05$ & $7.64 \pm 0.01(3)$ & $7.55 \pm 0.02(3)$ & $7.58 \pm 0.09$ & $7.51 \pm 0.10(3)$ & Morphine $10 \mu \mathrm{M}$ \\
\hline & $7.80 \pm 0.02$ & $7.59 \pm 0.12(3)$ & $7.66 \pm 0.02(3)$ & $7.66 \pm 0.13(3)$ & $7.82 \pm 0.15(3)$ & Carbachol $1 \mathrm{mM}$ \\
\hline & $7.88 \pm 0.03(3)$ & $7.48 \pm 0.03(3)^{*}$ & $7.28 \pm 0.06(3)^{*}$ & $7.24 \pm 0.15(3)^{*}$ & $7.24 \pm 0.13(3)^{*}$ & $\begin{array}{l}\text { Morphine } 10 \mu \mathrm{M} \\
\text { Carbachol } 1 \mathrm{mM}\end{array}$ \\
\hline \multirow[t]{3}{*}{$\%$ Not pre-treated $\mathrm{E}_{\max }$} & $100(3)$ & $103.68 \pm 1.63(3)$ & $100.51 \pm 2.70$ & $106.83 \pm 7.39$ & $105.73 \pm 5.67$ & Morphine $10 \mu \mathrm{M}$ \\
\hline & $100(3)$ & $101.32 \pm 8.76(3)$ & $97.04 \pm 1.79(3)$ & $105.43 \pm 0.79$ & $107.55 \pm 6.40(3)$ & Carbachol $1 \mathrm{mM}$ \\
\hline & $100(3)$ & $73.47 \pm 10.13$ & $69.33 \pm 9.06(3)$ & $84.82 \pm 18.36$ & $80.40 \pm 14.84$ & $\begin{array}{l}\text { Morphine } 10 \mu \mathrm{M} \\
\text { Carbachol } 1 \mathrm{mM}\end{array}$ \\
\hline
\end{tabular}


Table 2.

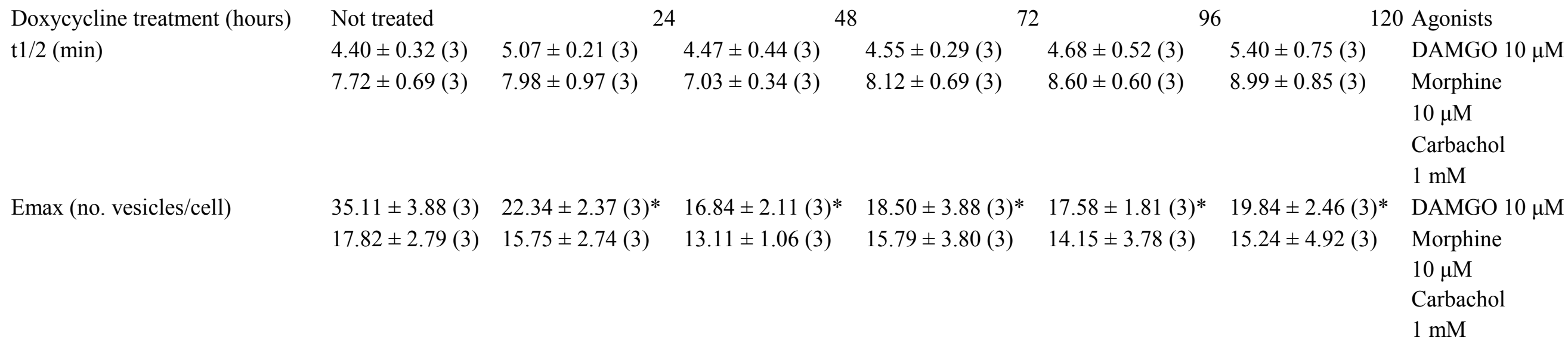




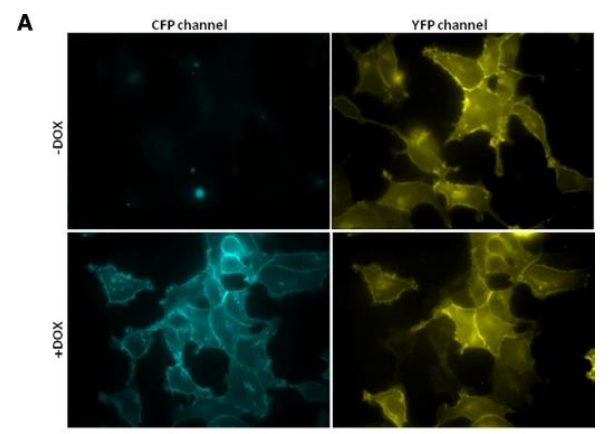

B

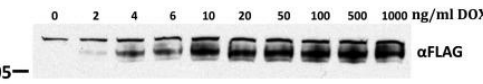

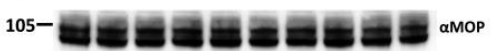

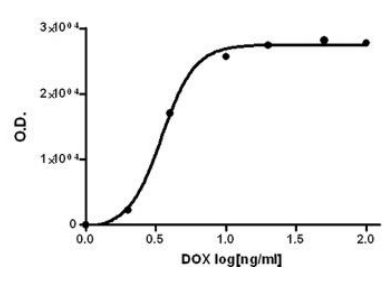

Fig. 1. 


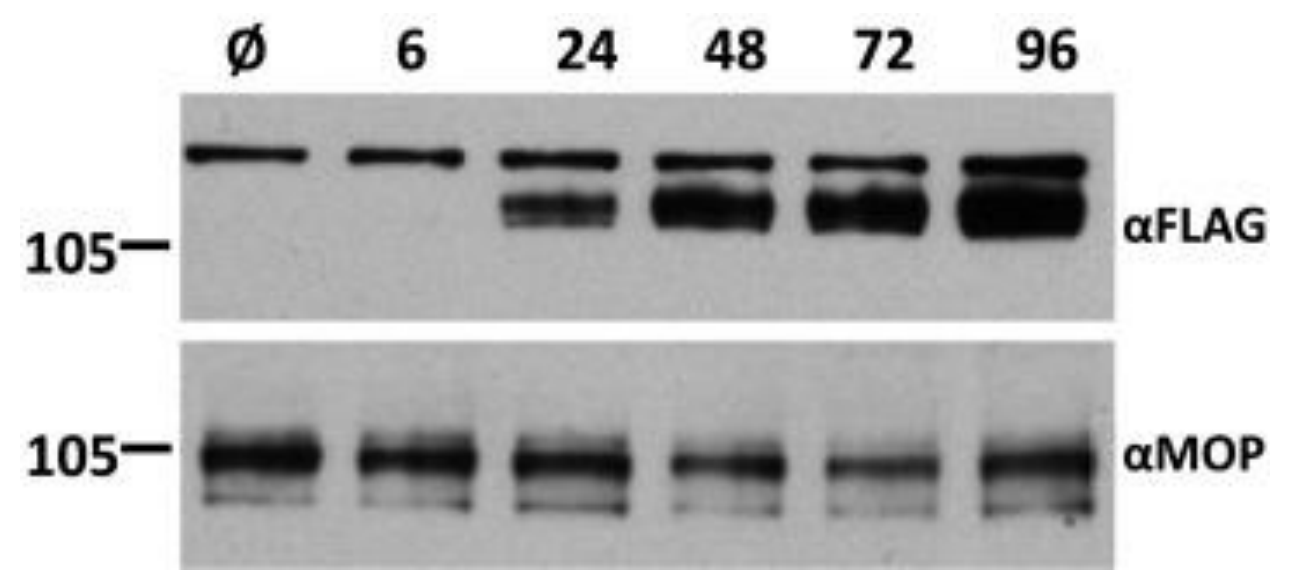

Fig. 2. 
A

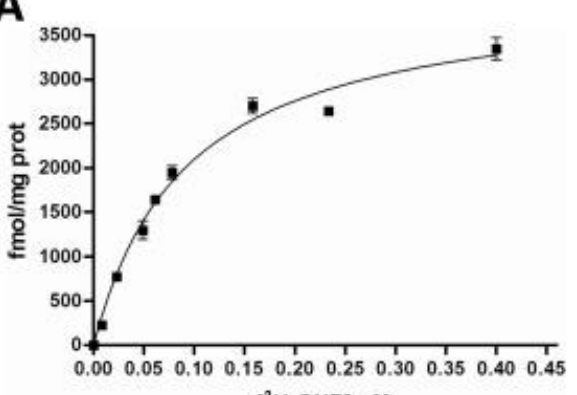

${ }^{3} \mathrm{H}$-QNB] nM

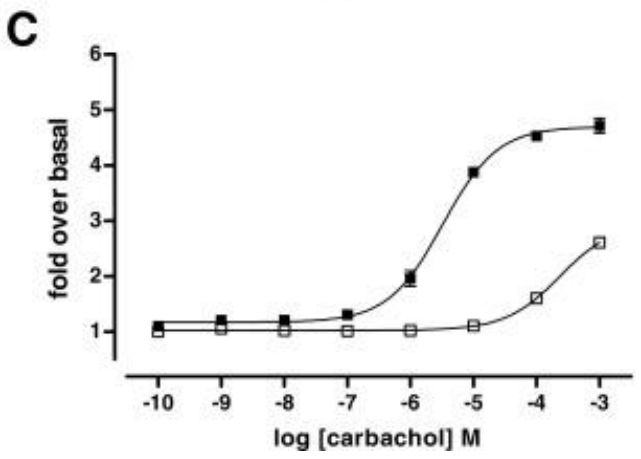

B

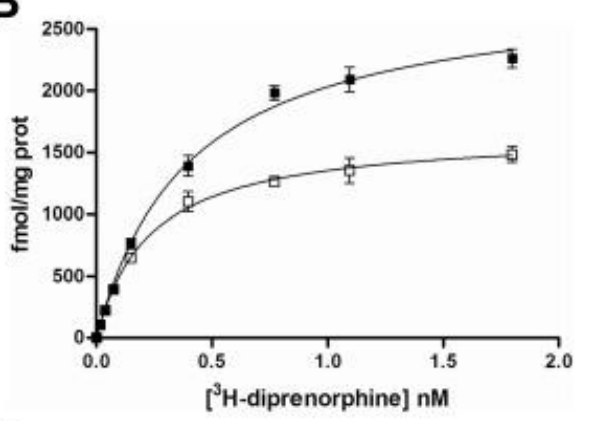

D

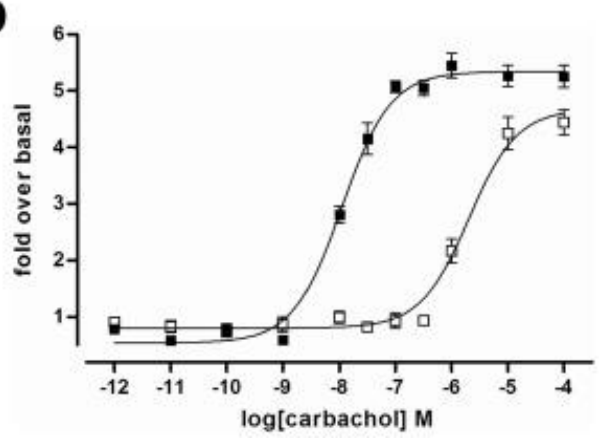

Fig. 3. 


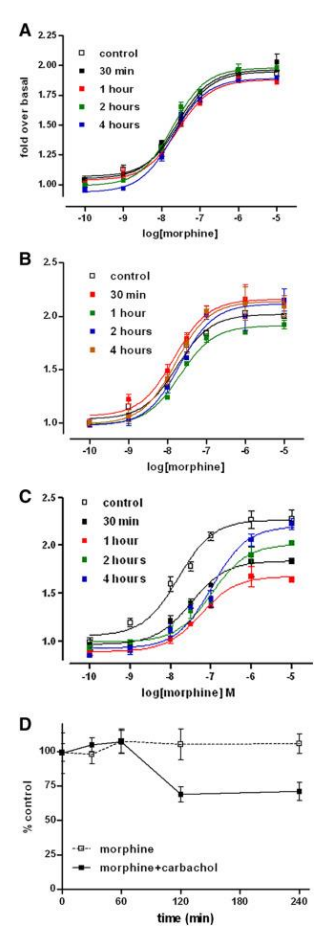

Fig. 4. 

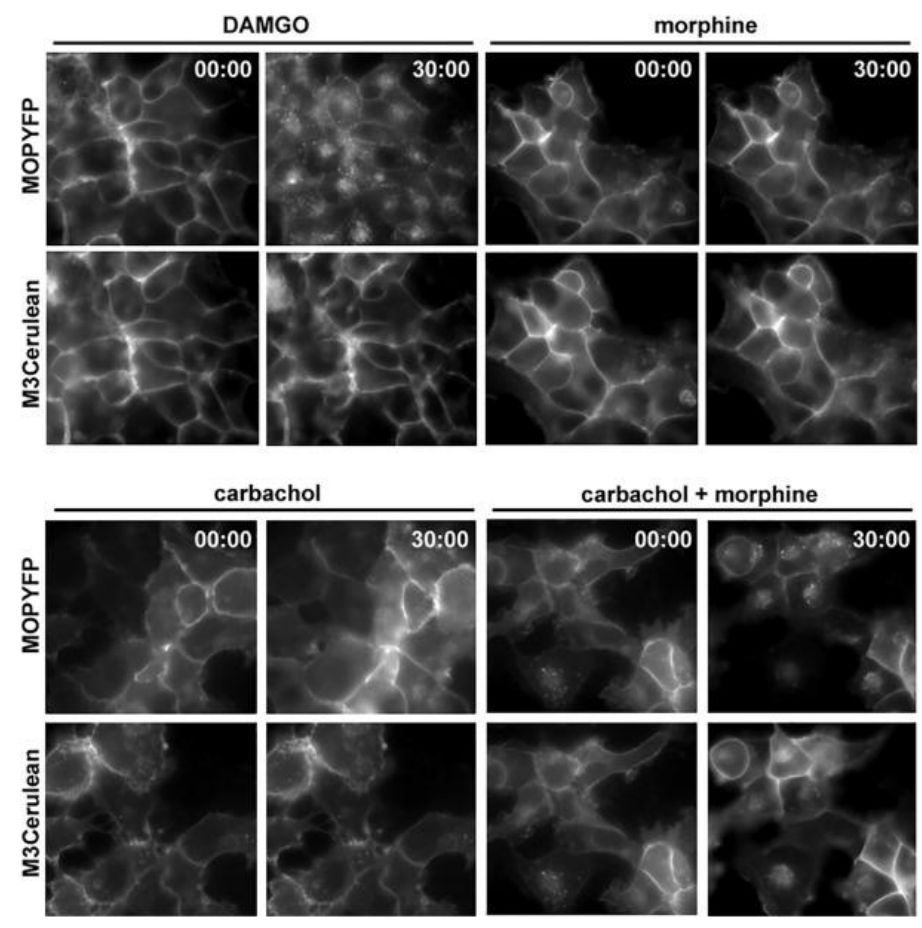

Fig. 5. 

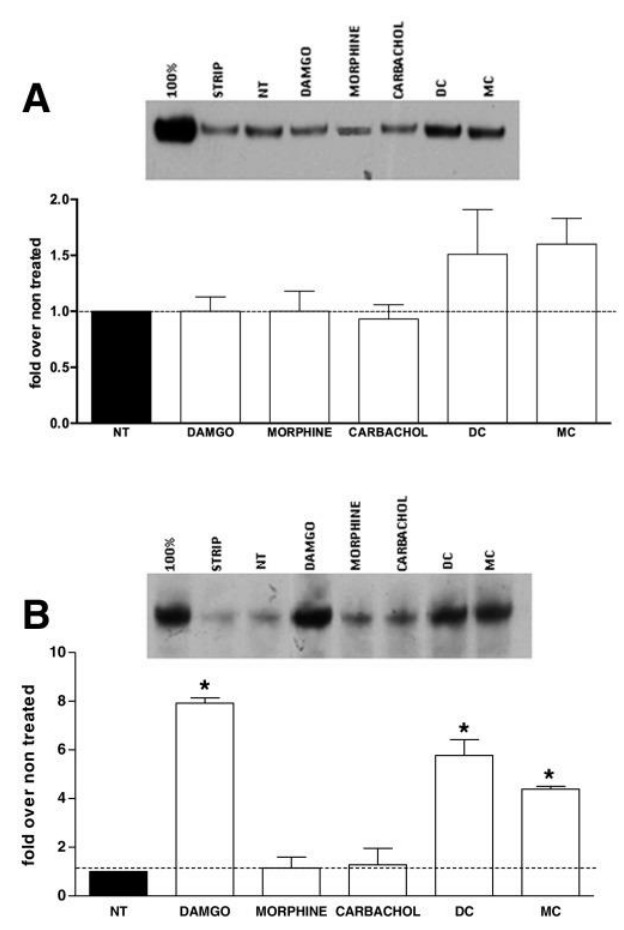

Fig. 6. 


$$
\text { 1..1!1!!! }
$$

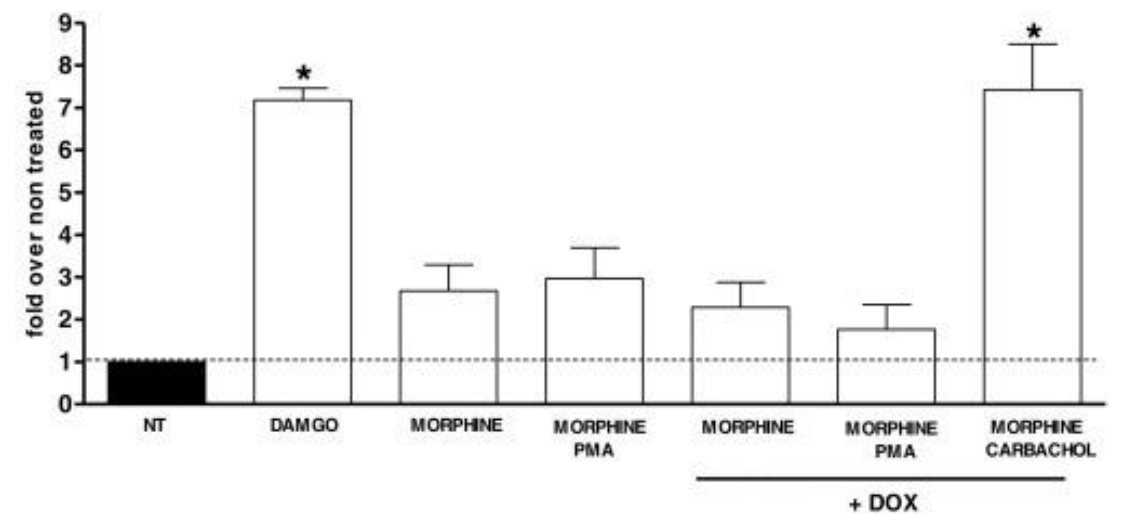

Fig. 7. 


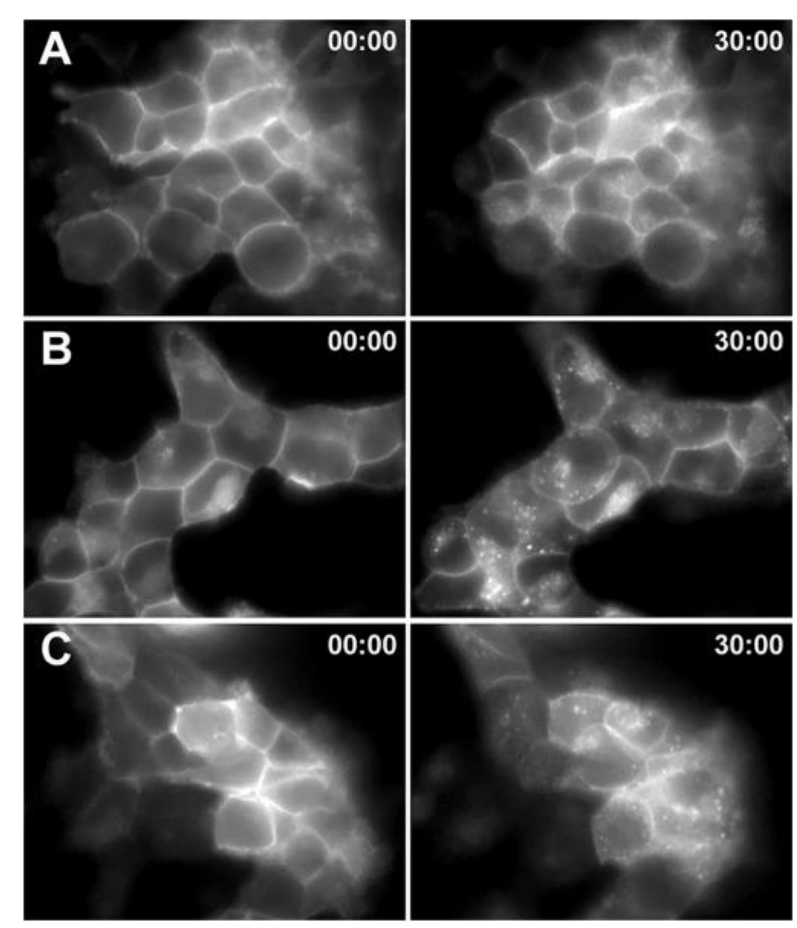

Fig. 8. 
A

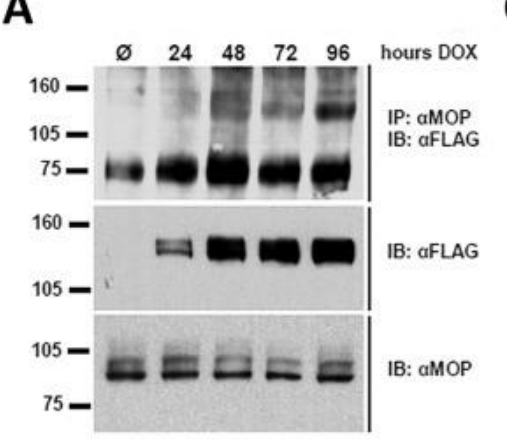

C

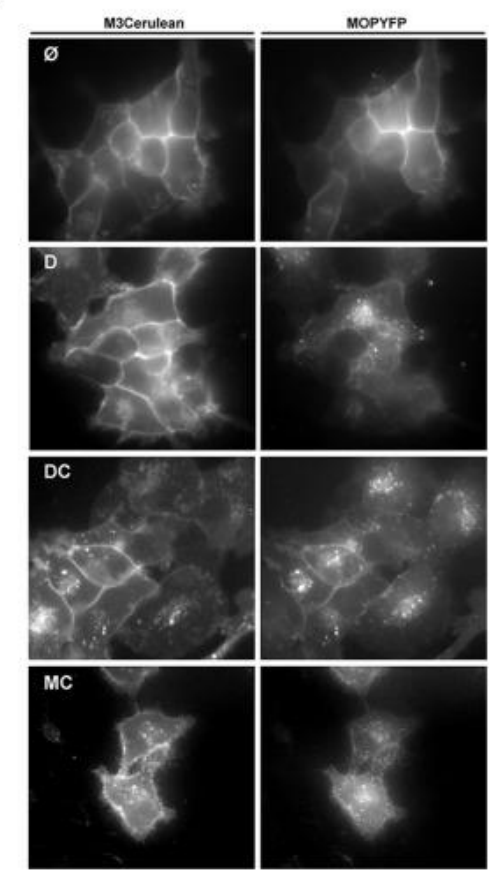

Fig. 9.

B

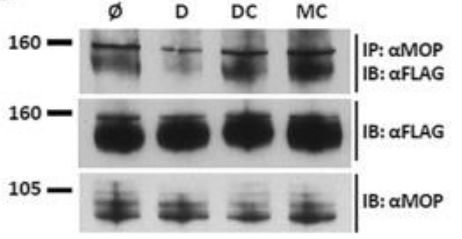




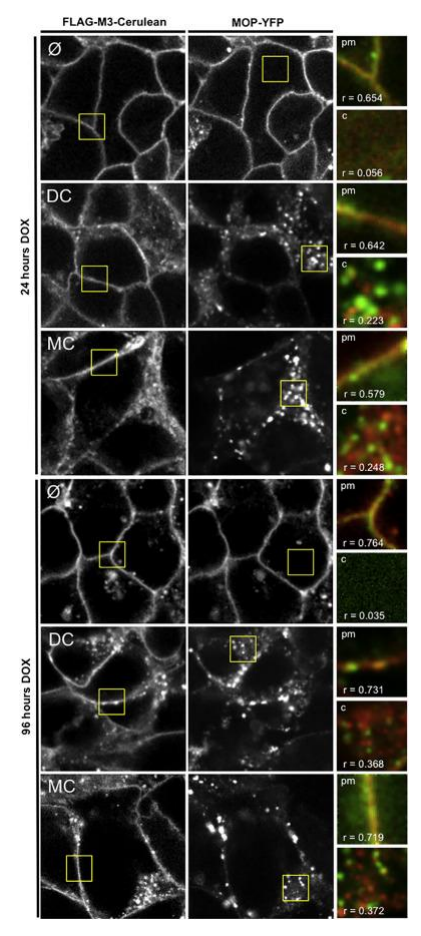

Fig. 10. 